\title{
Analysis of the global second-order effects on irregular reinforced concrete structures using the natural period of vibration
}

\section{Análise dos efeitos globais de segunda ordem em estruturas irregulares em concreto armado utilizando o período natural de vibração}
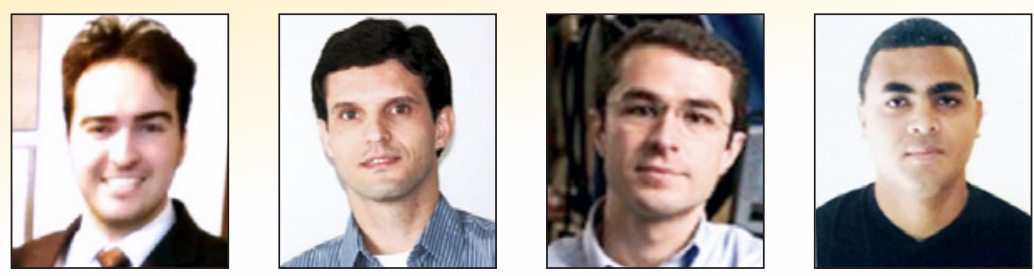

F. F. LEITÃO

fabiofleming@gmail.com https://orcid.org/0000-0001-6500-2160

G. H. SIQUEIRA a siqueira@fec.unicamp.br https://orcid.org/0000-0002-2416-1701

L. C. M. VIEIRA JR. a vieira@fec.unicamp.br https://orcid.org/0000-0002-0994-3473

S. J. C. ALMEIDA a saulojca@unicamp.com https://orcid.org/0000-0003-4037-5440

\begin{abstract}
The $\chi_{T}$ parameter, a simplified method recently presented, allows to estimate the global second-order effects on reinforced concrete frames using the natural period of vibration. This parameter was developed based on the fact that both natural period of vibration and global second-order effects depend essentially on the stiffness and mass matrices of the structure, being thus related. In this paper, numerical analyses are conducted on nine models with different patterns of irregularity in terms of geometry in plan and stiffness. The main purpose of these analyses is to evaluate the applicability of the $\chi_{T}$ parameter in asymmetric structures as well as that can present torsional modes as the fundamental mode of vibration. In addition, different hypotheses are tested in order to verify the influence of the different modes of vibration in the structural sensitivity to global second-order effects. Results of the simplified analyses were compared to the final bending moment values obtained through a nonlinear numerical analysis considering the P- $\Delta$ effect. It is observed that the parameter $\chi_{T}$ is a promising indicator for a simplified estimation of the global secondorder effects for concrete frames, especially when higher modes of vibration are taken account in the analysis.
\end{abstract}

Keywords: global second-order effects, natural period of vibration, modal analysis.

\section{Resumo}

O parâmetro $\chi_{T}$, recentemente apresentado na literatura técnica, permite utilizar o período natural de vibração da estrutura para estimar os efeitos globais de segunda ordem em pórticos de concreto armado. Esse parâmetro foi desenvolvido a partir da observação de que os efeitos de segunda ordem e o período natural de vibração dependem essencialmente da matriz de massa e rigidez da estrutura, estando, portanto, relacionados. Neste trabalho são realizadas análises numéricas em nove modelos de geometrias com diferentes padrões de irregularidades em planta e em termos de rigidez, com o intuito de avaliar a aplicabilidade do parâmetro $\chi_{T}$ em estruturas que possuem geometrias assimétricas e que possam apresentar modo fundamental de vibração do tipo torcional. Além disso, diferentes hipóteses são testadas para utilização desse parâmetro com o propósito de verificar a influência dos diferentes modos de vibração das estruturas na sensibilidade aos efeitos globais de segunda ordem. Os resultados das análises simplificadas foram comparados aos valores de momentos finais obtidos através de analises numéricas não lineares, considerando o efeito P- $\Delta$. Observa-se que o parâmetro $\chi_{T}$ apresenta-se como um promissor indicativo para estimativa dos efeitos globais de segunda ordem, principalmente quando os seus modos de vibração superiores são levados em consideração na análise.

Palavras-chave: efeitos globais de segunda ordem, periodo natural de vibração, análise modal 


\section{Introduction}

In the latest years, computational advancement and improvement of the material technology lead to the design of slender buildings more susceptible to global second order effects. Enhancement in computer's processors also enabled more complex structural analysis that were not assessed in the past because of limited computational resources. Along with this, using high-strength concretes allows the construction of higher buildings, which are consequently, more flexible [1].

Taller structures are subjected to higher horizontal forces, due to wind load. The combination of these forces with vertical loadings results in higher displacements of structural nodes and, consequently, significant increase of bending moment in its elements. Therefore, the structure must be assessed in its deformed shape. The additional forces from this analysis are known as the second-order moments [2]. In order to ensure structural safety, this geometrical nonlinearity must be considered in the structural stability analysis.

In addition, reinforced concrete frames have a nonlinear material behavior. Concrete cracking, concrete creep and, the rebar yielding are known as material physical nonlinearities [3]. Excessive lateral displacement must be verified considering both geometrical and material nonlinearities.

An option for the second-order analysis is to adapt the stiffness matrix $(K)$ to include second-order effects [4]. In this method, the stiffness matrix $(K)$ is composed by the elastic stiffness matrix $\left(K_{E}\right)$ and geometric stiffness matrix $\left(\mathrm{K}_{\mathrm{G}}\right)$; this problem are usually solved through iterative incremental methods [5]. In structures with multiple degrees of freedom, however, incremental method has high computational cost.

Therefore, direct and simplified methods are preferred to the second-order analysis. These methods adopt approximations and simplifications to describe the structural behavior; their efficiency relies on the selection of the most important variables and its influence on the structural behavior. Although these procedures are simplified, they can be quickly applied and provide satisfactory results [6].

Rutenberg [7] proposed a direct approach to obtain the global second-order effects. The stiffness matrix is modified through the insertion of fictitious diagonal braces and columns with negative cross section area and flexural stiffness, respectively. The fictitious elements simulate the geometric stiffness matrix, which includes second-order effects while equilibrium is verified. Thus, a linear analysis can be carried out and no iterations are needed. Wilson and Habilullah [8], White et al. [9], [10] and Vandepitte [11] are other examples of direct approaches.

Simplified methods are also included in many countries design standards. The American standard AISC/LRFD [12] introduces B1 and B2 coefficients to evaluate second-order effects in steel structures. The second-order forces are obtained through linear analysis and, are vastly used by steel structural design engineers. To define the requirement of second-order analysis, ABNT NBR 6118:2014 [2] adopts the simplified parameters $\alpha$ and $\gamma_{z}$. Parameter a classify the structure as nonsway or sway frames. Global second-order effects can be neglected for the latter.
The $\gamma_{z}$ coefficient [13], besides providing a classification regarding structural susceptibility to second order effects, it is also used to estimate second-order forces through first-order analysis. ABNT NBR 6118:2014 [2] allows material nonlinearity to be considered applying reduction factors to the element stiffness. It estimates the structural elements stiffness change and assumes different values for each type of element.

The coefficient $\gamma_{z}$ is calculated assuming that lack of stability will only occur laterally without rotational component. Structures, which the center of mass does not correspond to the center of rigidity, however, may present as the first stability mode the torsional mode. In this case, stability analysis with this coefficient may not be sufficient to assess structural integrity [14]. Therefore, to apply $\gamma_{z}$ coefficient, stability modes must also be assessed.

Buildings global stability is mainly influenced by lateral stiffness and vertical loads applied [15]. Based on this, Statler et al. [16] have demonstrated that it is possible to evaluate the structure susceptibility to global second order effects using the natural period of vibration in steel structures.

Recently, Reis et al. [17] presented the development of the simplified $\chi_{T}$ parameter. This parameter uses the natural period of vibration to estimate bending moments considering non-linear effects. To account for the global second-order effects, first-order moments are amplified in reinforced concrete frames. Analyses carried out by Reis et al. [17], however, applied the $\chi_{T}$ parameter only in structures with floor plan symmetry and no stiffness variation along its height. These characteristics diverge completely from most constructions. In Brazil, floor plan designs are usually asymmetric, which leads to: (i) asymmetrical structures, that have eccentricity between the center of mass and center of rigidity and makes the structure vulnerable to significant torsional forces, (ii) vertical stiffness variation along the building's height caused by the sudden change in geometry between two floors or change in the cross-section area, (iii) bracing elements non-parallel or non-symmetric to principal axes, and, (iv) structures with multiple floor plan that do not have the same projection.

Thus, it is essential, to validate the parameter $\chi_{T}$, that a greater number of analysis are carried out considering structural models with similar characteristics to existing buildings. Furthermore, results obtained by Reis et al. [17] presented conservative values for the critical columns on the assessed models. Therefore, an improvement in moment amplification methods due to global secondorder effects must be investigated.

In the field of structural dynamics, modal superposition is commonly used. The total structure's response is obtained by superposing the response for each mode shape. Therefore, parameter $\chi_{T}$ can be improved considering higher vibration modes.

In this context, the current work aims to assess the application of the $\chi_{T}$ parameter, developed by Reis et al. [17], in reinforced concrete structures with different irregularities on the floor plan and, along its height. The study presented herein is intended to cover the major structures designed in Brazil and, to understand the limitation of the methods. Two new hypotheses are developed and verified. The importance of the mode shape direction in the application of the simplified parameter is assessed, as well as, the influence of higher frequency modes. 


\section{2. $\chi_{T}$ Parameter}

The $\chi_{T}$ parameter was developed by Reis et al. [17] aiming to evaluate reinforced concrete structures susceptibility to global secondorder effects; in addition, it is possible to estimate the final internal forces through a simplified first-order analysis. The parameter was developed applying Rayleigh's method [18], in which coordinate generalization and the principle of virtual work were used. Rayleigh's method [18] is based on the principle of energy conservation. If the physical properties are known, the natural period of vibration of an element can be estimated by the selection of a displacement function $(\psi)$ that respects the essential and/or natural boundary conditions.

In Rayleigh method [18], a satisfactory approximation for the structure fundamental period of vibration is obtained adopting any displacement function that satisfies the essential (kinematic) boundary conditions. Adopting, however, a shape function that does not satisfies the natural boundary conditions, impose additional restrains and external constrained to the system [19]. These restrictions increase the system stiffness and, consequently, influence significantly on the natural period of vibration estimated by the method.

The $\chi_{T}$ parameter theoretical basis relies on the application of generalized coordinates to represent the dynamic displacement of a cantilever beam-column, with mass and stiffness equivalent to a regular structure. The column is subjected to a uniform distributed horizontal loading $F(x)$ along its height. The floor masses $\left(m_{p}\right)$ are concentrated along its length with constant spacing of $3,0 \mathrm{~m}$. The column mass $\bar{m}$ is uniformly distributed along the column height. The model representation is shown in Figure [1]. The $\chi_{T}$ parameter complete original formulation obtained by Reis et al. [17] is presented in Equation [1]:

$$
\frac{M_{2}}{M_{1}}=\chi_{T}=\frac{1}{1-\frac{g T^{2}}{H \pi^{2}\left(\frac{72 n^{4}+\kappa_{p a v}\left(180 n^{3}+120 n-12\right)}{36 n^{4}+9 n^{3}+n^{2}-n}\right)}}
$$

Onde,

$\mathrm{M}_{1}$ - First-order moment;

$\mathrm{M}_{2}$ - Final second-order moment;

$\mathrm{H}$ - Building's height;

$\mathrm{T}$ - Natural period of vibration;

$\mathrm{n}$ - Number of floors;

$\mathrm{g}$ - Acceleration of gravity;

$\mathrm{K}_{\text {pav }}$ - Ratio between the sum of all floor weight and the structure total weight.

A simplification was developed based on the influence of each $A$ simplification was developed based on the influence of each polynomial term of the original equation and adopting $\mathrm{k}_{\mathrm{pav}}$ equal to 0,80 . The complete and simplified equation presented a maximum divergence of $1,5 \%$. The equation details, as well as simplification, can be found in Reis et al. [17]. The $\chi_{T}$ parameter final version is presented in Equation [2]:

$$
\chi_{T}=\frac{1}{1-\frac{g T^{2}}{H \pi^{2}\left(2+\frac{4}{n}\right)}}
$$

Equation [2] depends essentially on the natural period of vibration, building's height and number of floors. The generalized system adopted by Reis et al. [17] for the development of the $\chi_{T}$ parameter suppose that the fundamental mode of vibration is flexural. Thus, the natural period of vibration adopted to global second-order analysis must be related to the first flexural mode of vibration in each assessed direction. Then, the natural period of vibration adopted in the $\chi_{T}$ parameter equation for moment amplification $\left(M_{2} / M_{1}\right)$ must be related to this vibration mode.

Reis et al. [17] assessed the $\chi_{T}$ parameter for five different structure models with one axis of symmetry at least. The moment amplification results were compared with the results of a P- $\Delta$ second-order analysis. It was shown that the simplified $\chi_{T}$ parameter represents well the second-order effects in reinforced concrete structures. The authors, however, commented that more studies must be carried out to adjust and validate the simplified methodology, mainly on the application of irregular structures which can be vulnerable to torsional effects.

In addition, the $\chi_{T}$ parameter values presented by the models in Reis et al. [17] were conservative for the critical columns. The adopted displacement function does not satisfy the natural boundary conditions, which leads to a conservative moment amplification for the critical columns.

Mamone et al. [20] extended $\chi_{T}$ parameter using a displacement function that satisfies simultaneously essential and natural conditions, which lead to a more flexible system. Considering this adaptation, the $\chi_{T}$ parameter application was assessed in two simplified models. The first model is a cantilever beam-column and the second model is a simple frame with regular geometry. The results obtained for the moment amplification were closer to the values obtained for the critical columns; the models studied, however, present floor plan symmetry and the stiffness does not vary along its height.

The $\chi_{T}$ parameter equation can also lead to greater values when considering a modified period of vibration with the superposition of

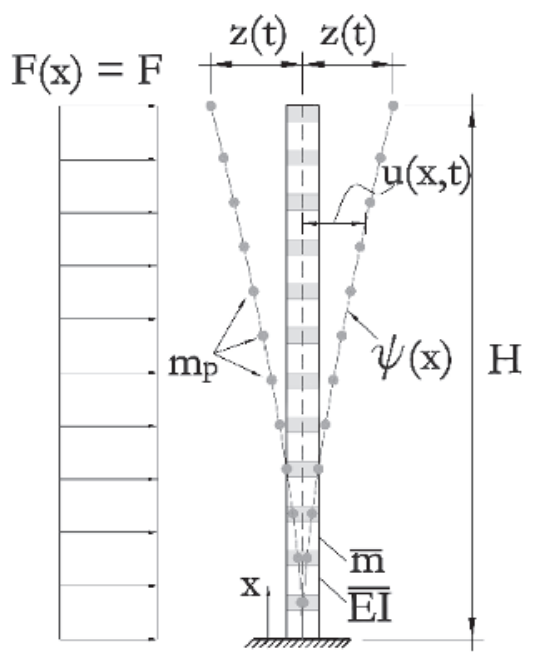

Figure 1

Generalized model adopted by Reis et al. (2017)

Source: Reis et al. (2017) 


\section{Model 1}
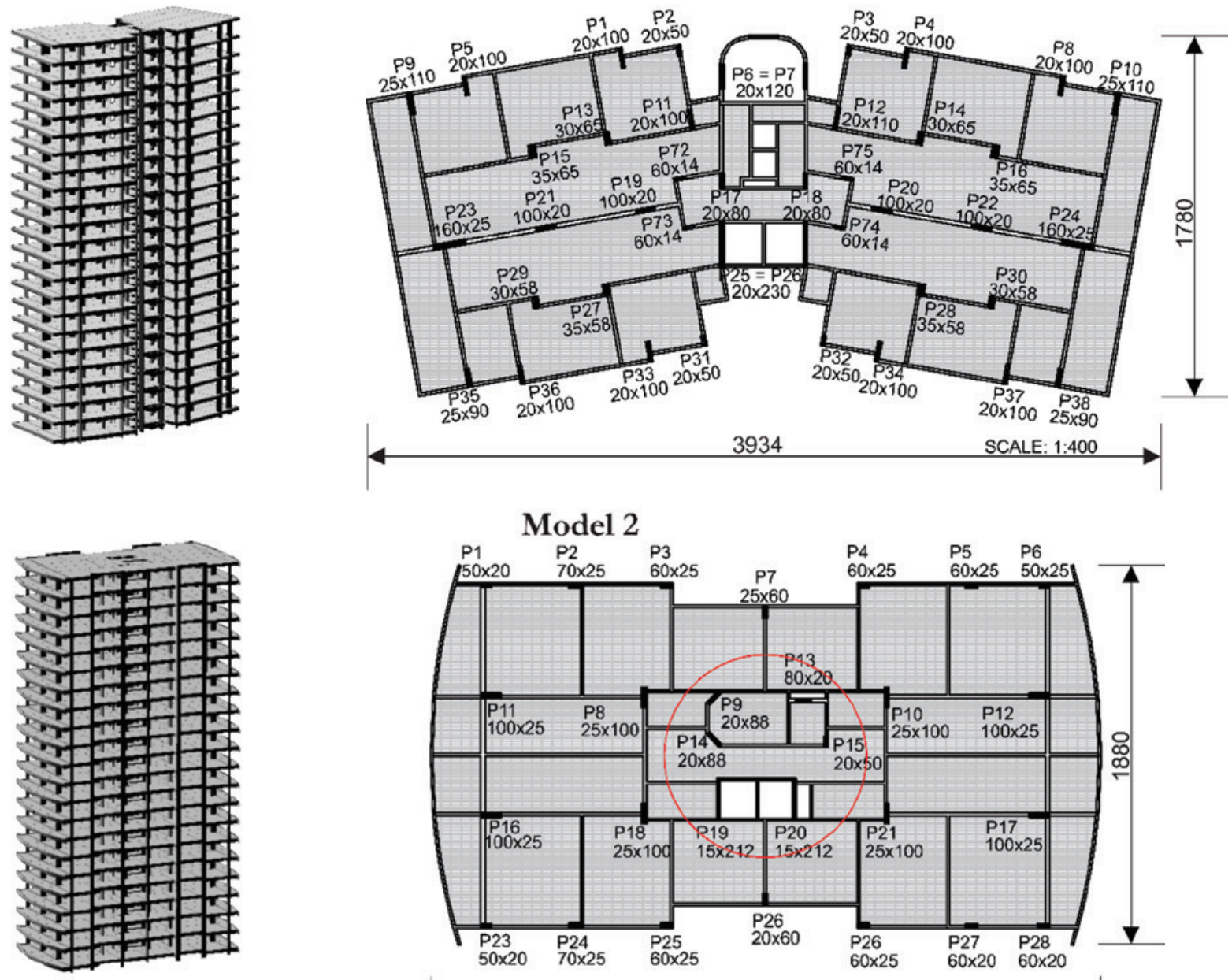

Model 2
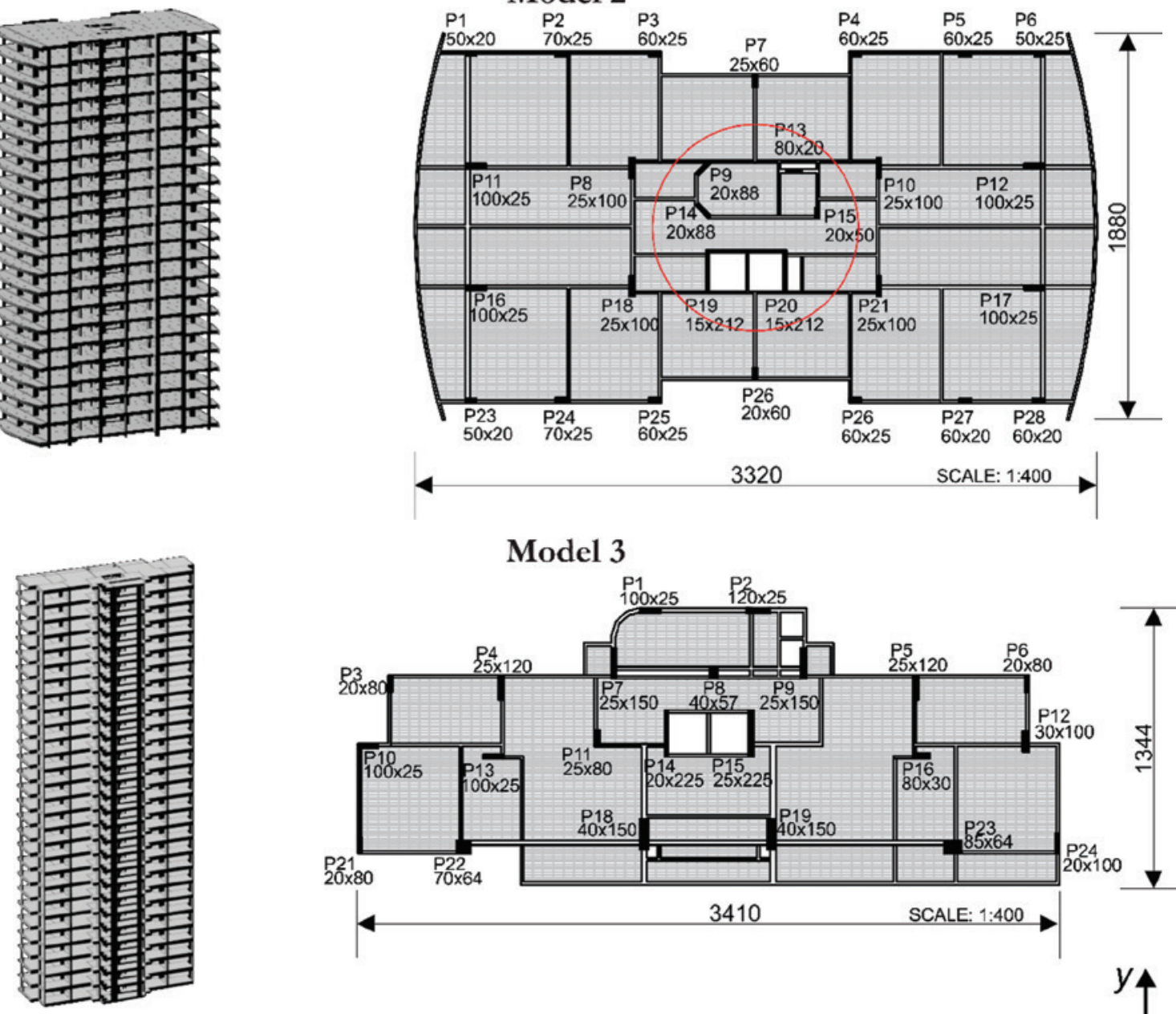

Model 3
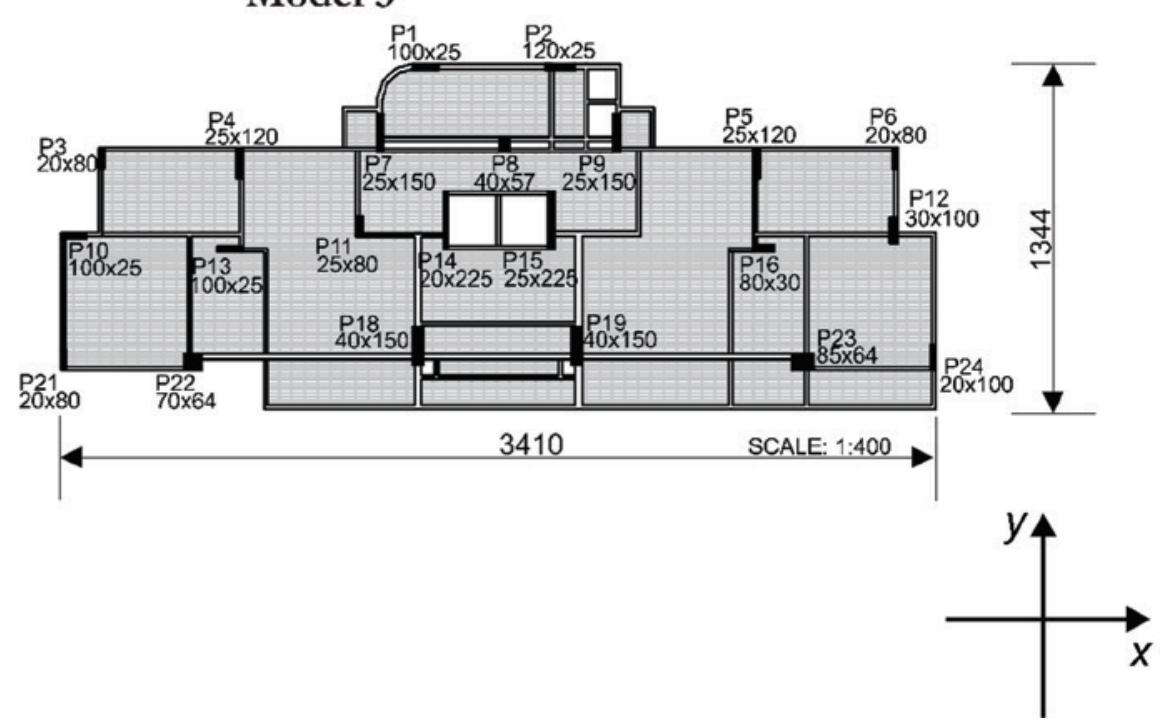

Figure 2

Models 1, 2 and 3 geometries 

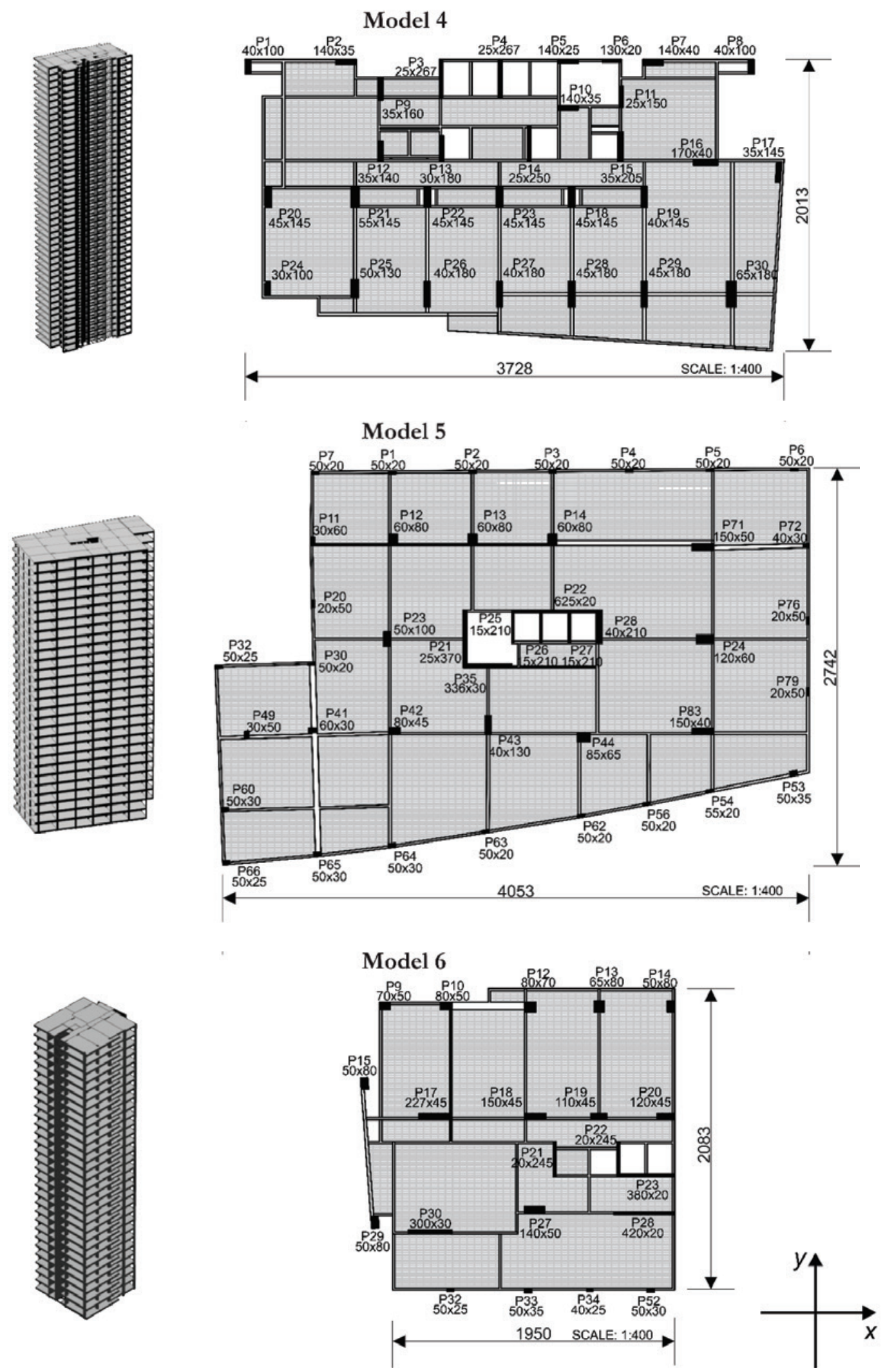

Figure 3

Models 4, 5 and 6 geometries 
kinematic mode shapes of the structure (vibration modes). Thus, the moment amplification due to global second-order effect can be estimated considering natural period of vibration related to superior vibration modes.

The current study intends to contribute to the verification of the method's limit of application and, to its development. The parameter is applied: (i) in new structural models with different patterns of irregularities on the floor plan and (ii) stiffness variation along the building's height, and (iii) in structures vulnerable to torsional forces, which the first mode of vibration is torsional.

Two new hypotheses are developed and tested to consider higher vibration modes in the $\chi_{T}$ parameter equation. The hypotheses present criteria that, based on the effective modal mass, select the natural period of vibration to be applied in the
$\chi_{\mathrm{T}}$ parameter equation. These hypotheses are explained later in the following section.

\section{Methodology}

\subsection{Model description}

Spatial frames with different geometries and irregularities on its floor plan or along the building's height were modelled herein and, are presented in Figures [2] to [6].

The models have multimodal characteristics, which assist the assessment of the influence of higher vibration modes on the proposed simplified parameter. Models 7 and 8 are real structures designed in Brazil, aimed to allow a realistic study of the parameter $\chi_{\mathrm{T}}$. Observing the geometry of both structures (Figure [4] and

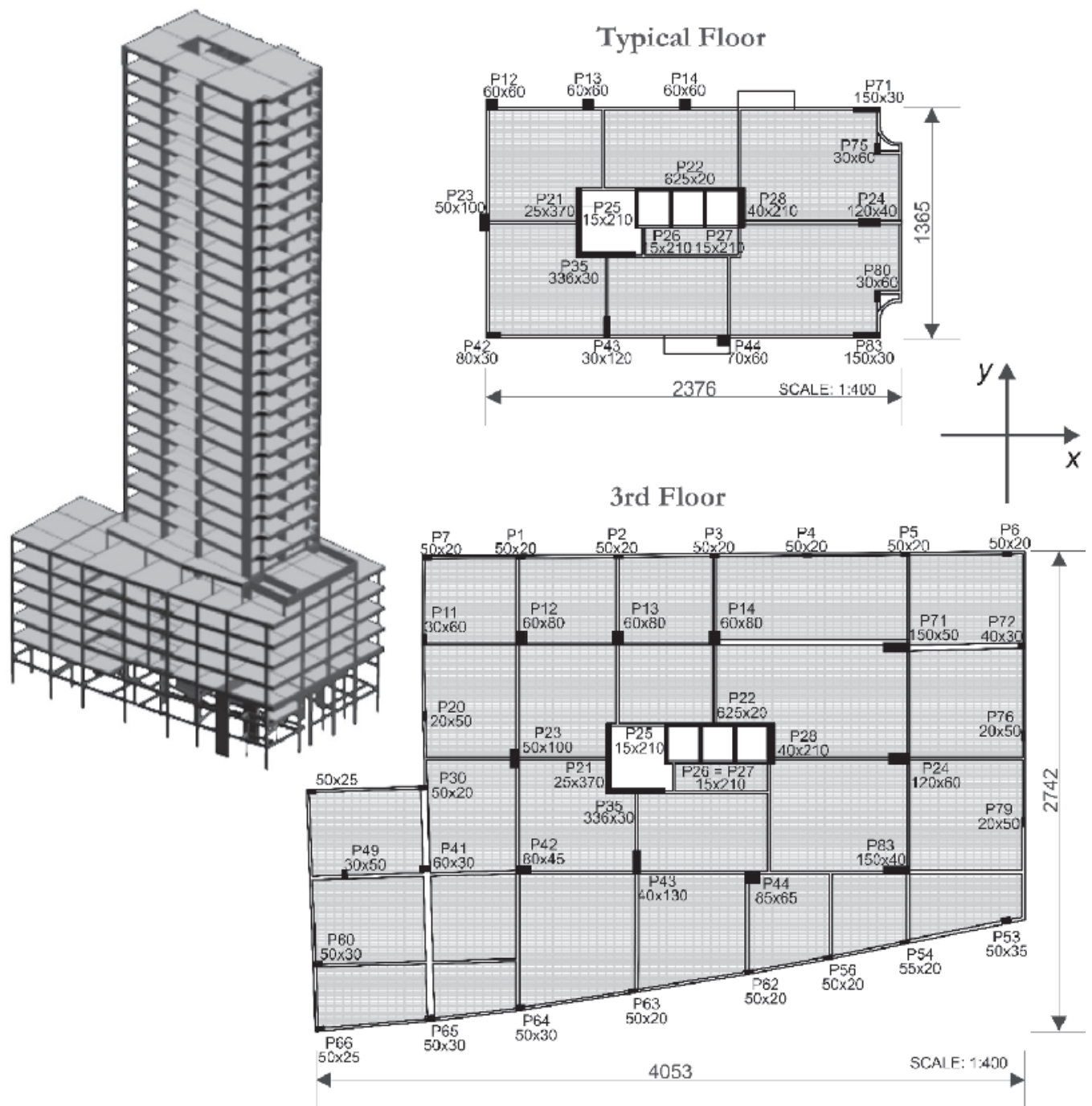

Figure 4

Model 7 geometry 
[5]), one can note that there are many stiffness variations between floors. These geometry variations characterize a stiffness variation along the building's height. Thus, models 7 and 8 will contribute to evaluate the parameter $\chi_{T}$ application in structures with this type of irregularity.

All models were generated with the software S4 [21] used in

Model 8

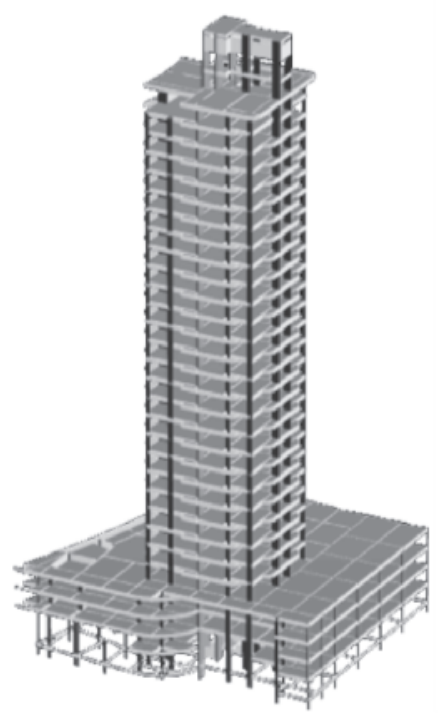

Typical Floor
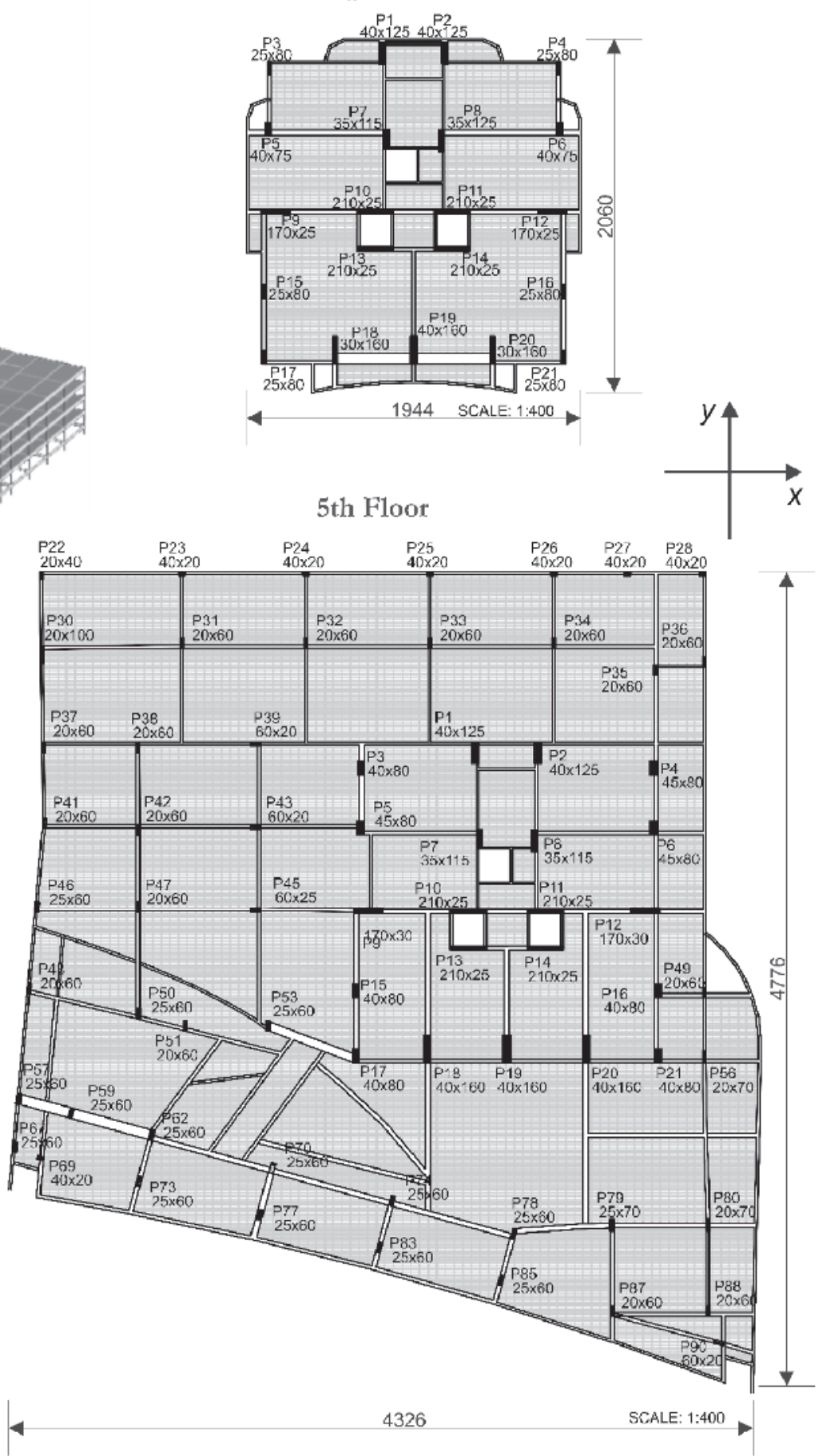

Figure 5

Model 8 geometry 
the structural design of reinforced concrete structures. All geometries were assessed varying the number of floors until the $\gamma_{z}$ coefficient reached the limit value of 1.3 . This is the maximum value allowed in the application of the simplified method suggested by ABNT NBR 6118:2014 [2]. Model 4 was an exception to this $\gamma_{z}$ limitation, a limit of 1.2 was imposed since the building height respective to this value was already considered too high.

The models' characteristics are summarized in Table [1]. The number of floors, maximum height, material mechanical properties, vertical loading per floor and, $\gamma_{z}$ value for both orthogonal directions in the plan $(x$ and $y)$ are presented.

\subsection{Design Considerations}

After defining the maximum number of floors, the software S4 [21] model was exported to SAP2000 [22] software. SAP2000 [22] is a finite element software extensively used by structural designers worldwide because of its user-friendly interface to carry out linear, nonlinear and modal analysis. In SAP2000 [22], columns and beams are modelled as unidimensional elements (beam element). These elements have six degree of freedom per node; three translations and, three rotations. Due to slabs' high horizontal stiffness, they are modelled as rigid diaphragms. Thus, the slabs behave similarly to a rigid body that does not deform axially [23].

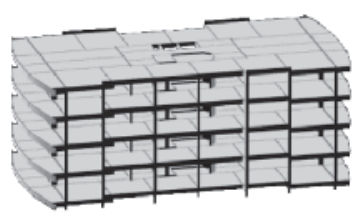

Model 9

\section{Ground Floor - 4-Storey}

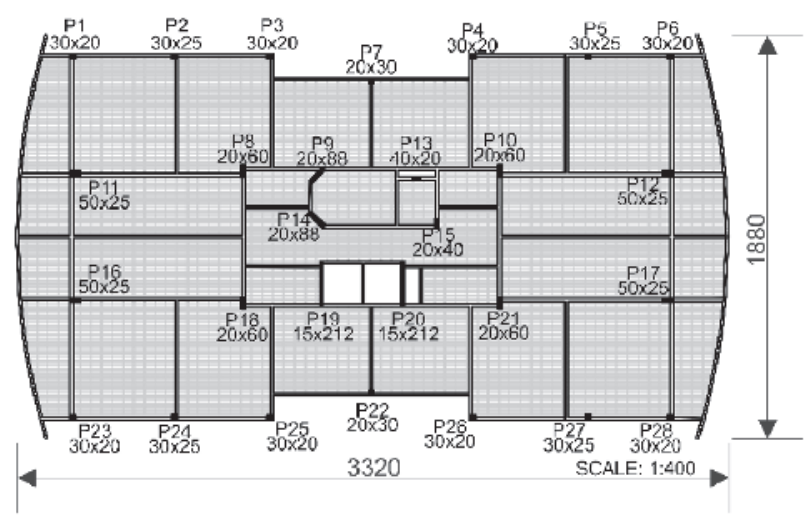

\section{Ground Floor - 21-Storey}
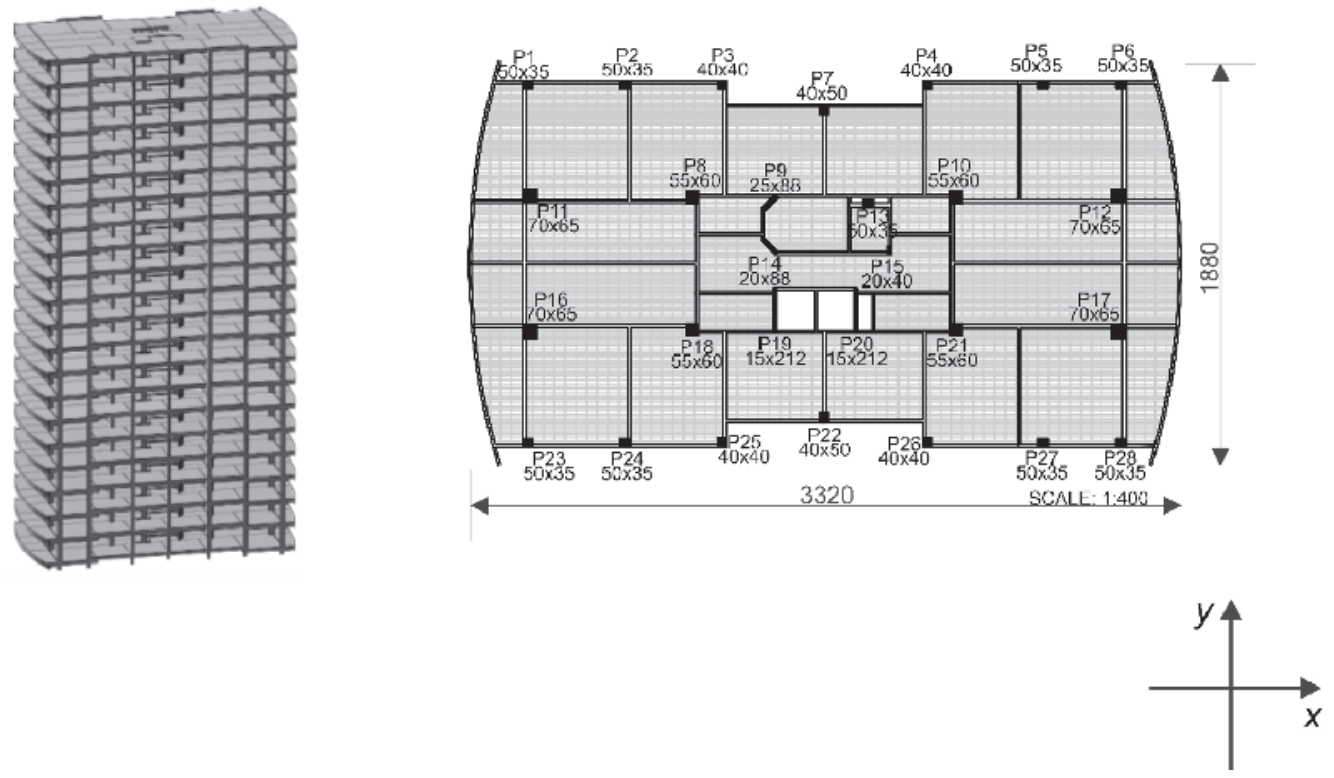

Figure 6

Model 9 geometry 
Table 1

Assessed models characteristics

\begin{tabular}{|c|c|c|c|c|c|c|c|}
\hline Model & $\begin{array}{l}\text { Maximum } \\
\text { number } \\
\text { of floors }\end{array}$ & $\begin{array}{l}\text { Total height } \\
(\mathrm{m})\end{array}$ & $\begin{array}{l}\text { Characteristic } \\
\text { compressive } \\
\text { strength } \\
\text { (MPa) }\end{array}$ & $\begin{array}{l}\text { Modulus of } \\
\text { elasticity } \\
\text { (MPa) }\end{array}$ & $\begin{array}{l}\text { Vertical } \\
\text { loading } \\
\text { per floor } \\
\text { (kN/floor) }\end{array}$ & $\gamma_{z}(\mathbf{x})$ & $\gamma_{z}(y)$ \\
\hline 1 & 22 & 66.0 & 25 & 23,800 & 5,650 & 1.16 & 1.32 \\
\hline 2 & 21 & 63.0 & 25 & 23,800 & 3,720 & 1.18 & 1.29 \\
\hline 3 & 28 & 84.0 & 25 & 23,800 & 3,220 & 1.20 & 1.31 \\
\hline 4 & 43 & 129.0 & 25 & 23,800 & 8,690 & 1.20 & 1.18 \\
\hline 5 & 27 & 81.0 & 35 & 28,161 & 13,460 & 1.16 & 1.27 \\
\hline 6 & 30 & 90.0 & 35 & 28,161 & 4,570 & 1.16 & 1.31 \\
\hline 7 & 30 & 90.0 & 35 & 28,161 & $\begin{array}{c}5,070 \\
\text { (typical floor) }\end{array}$ & 1.17 & 1.26 \\
\hline 8 & 33 & 66.0 & 35 & 28,161 & $\begin{array}{c}4,580 \\
\text { (typical floor) }\end{array}$ & 1.15 & 1.11 \\
\hline 9 & 21 & 63.0 & 25 & 23,800 & 3,720 & 1.19 & 1.27 \\
\hline
\end{tabular}

Load cases and loading combinations were also exported from S4 software [21]. Loading combinations include the effects of simultaneous application of vertical (dead and live loads) and horizontal (wind load) loadings. For each wind loading direction, a different loading combination was created. The wind load was considered in the structure's principal directions $0^{\circ}(\mathrm{Fx}+), 90^{\circ}(\mathrm{Fy}-), 180^{\circ}(\mathrm{Fx}-)$ and $270^{\circ}(\mathrm{Fy}+)$, according to standard ABNT NBR 6123:1988 [24]. Figure [7] illustrates wind load directions considered in the models.

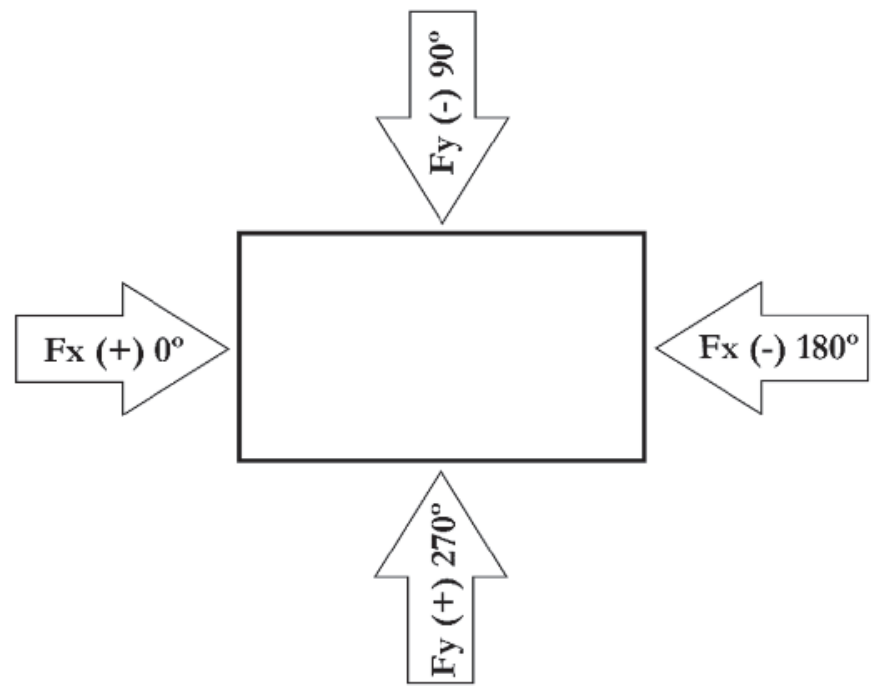

\section{Figure 7}

Principal directions considered for the lateral wind loading
Wind load magnitude were divided by pressure ranges according to each structure height, aimed to more realistic represent the wind pressure acting on the structure. To consider the rigid diaphragm effect, however, these loadings were modeled as concentrated horizontal forces in each floor level. All floor nodes displacements equivalent to the diaphragm center of mass displacement. Thus, concentrated horizontal loadings were applied in these nodes on each floor level.

The material nonlinearity was considered approximately using the reduction factors prescribed by ABNT NBR 6118:2014 [2]. The columns were considered encastred on the foundations.

For all loading combinations, two analyses types were carried out in SAP2000 [22]: considering only the overturning moment due to horizontal wind load, in order to obtain the first-order bending moments $\left(\mathrm{M}_{1}\right)$; and, a second analysis considering the $\mathrm{P}-\Delta$ effect to determine the second-order bending moments $\left(M_{2}\right)$. The obtained ratio between second-order and first order bending moments $\left(\mathrm{M}_{2} / \mathrm{M}_{1}\right)$ from both analyses express the moment amplification due to global second-order effects. P- $\Delta$ effect are taken in account in SAP2000 [22] considering a modified geometrical stiffness matrix $\mathrm{K}_{\mathrm{G}}$ in addition to the linear-elastic stiffness matrix $\mathrm{K}_{\mathrm{E}}$.

Simultaneously, modal analyses were carried out to determine the natural periods of vibration and its respective mode shapes, as well as the effective modal mass participation factor. Modal analysis, in SAP2000 [22], consists of a generalized eigenvalue problem, which the eigenvectors are orthogonal to mass and stiffness matrices. Free undamped systems are considered. The eigenvalues represent the natural period of vibration and their respective eigenvector are the vibration modes.

For each geometry studied, after defining the maximum height and the maximum number of floors, all analyses were repeated remov-

\section{Table 2}

Summary of each hypothesis for the natural period of vibration selection

\begin{tabular}{cc}
\hline Hypothesis & Description \\
\hline I & $1^{\text {st }}$ flexural mode in the considered direction - original hypothesis (REIS et al. [8]) \\
III & Average of the natural period of vibration weighted by effective modal mass \\
\hline
\end{tabular}


Table 3

Example of the first 12 modes of vibration of a 21-storey structure generated with Model 2

\begin{tabular}{ccccccc}
\hline \multirow{2}{*}{$\begin{array}{c}\text { Mode of } \\
\text { vibration }\end{array}$} & $\begin{array}{c}\text { Period } \\
\text { (s) }\end{array}$ & X-direction & Y-direction & $\begin{array}{c}\text { Accumulated } \\
\text { sum X-direction }\end{array}$ & $\begin{array}{c}\text { Accumulated } \\
\text { sum Y-direction }\end{array}$ & Z-rotation \\
\cline { 3 - 6 } & 7.09 & $0.09 \%$ & $72.38 \%$ & $0.09 \%$ & $72.38 \%$ & $42.75 \%$ \\
2 & 6.38 & $0.74 \%$ & $0.67 \%$ & $0.83 \%$ & $73.05 \%$ & $8.74 \%$ \\
3 & 5.70 & $75.58 \%$ & $0.05 \%$ & $76.41 \%$ & $73.10 \%$ & $23.66 \%$ \\
4 & 2.14 & $0.05 \%$ & $8.81 \%$ & $76.46 \%$ & $81.91 \%$ & $7.50 \%$ \\
5 & 2.07 & $0.05 \%$ & $2.70 \%$ & $76.51 \%$ & $84.61 \%$ & $0.01 \%$ \\
6 & 1.83 & $10.30 \%$ & $0.01 \%$ & $86.81 \%$ & $84.62 \%$ & $3.22 \%$ \\
7 & 1.21 & $0.03 \%$ & $0.19 \%$ & $86.84 \%$ & $84.81 \%$ & $1.14 \%$ \\
8 & 1.08 & $0.01 \%$ & $4.24 \%$ & $86.85 \%$ & $89.05 \%$ & $1.64 \%$ \\
9 & 1.02 & $3.60 \%$ & $0.02 \%$ & $90.45 \%$ & $89.07 \%$ & $1.22 \%$ \\
10 & 0.82 & $0.01 \%$ & $0.05 \%$ & $90.46 \%$ & $89.12 \%$ & $0.52 \%$ \\
11 & 0.69 & $1.96 \%$ & $0.01 \%$ & $92.42 \%$ & $89.13 \%$ & $0.45 \%$ \\
12 & 0.67 & $0.01 \%$ & $2.45 \%$ & $92.43 \%$ & $91.58 \%$ & $1.24 \%$ \\
\hline
\end{tabular}

ing one floor level until the structure had only one floor left. Therefore, 255 analyses were carried out herein.

In models 1 to 8 , the same structural configuration was adopted, independently of the number of floors. Model 9 has the same geometry of Model 2. For each analysis, the building structural elements were redesigned once a floor level was removed. Model 9 crosssection variation is depicted in Figure [6], in which the ground floor geometry for a 21-storey and 4-storey structures are presented. Therefore, Model 9, due to element redesign, also contributed to evaluate the $\chi_{T}$ parameter in realistic buildings. More details about the evaluated hypotheses are presented as follows.

\subsection{Hypotheses}

The original $\chi_{T}$ parameter hypothesis, presented by Reis et al. [17], shall consider the first flexural vibration mode according to the assessed direction. In order to verify the influence of different vibration modes to the global second-order effects, two hypotheses were proposed. Each one has specific criteria to select the natural period of vibration that will be used in the simplified $\chi_{T}$ parameter. Results are compared to the final moment amplification factors of the structures columns. Table [2] summarizes the hypotheses for the natural period of vibration selection, including the original hypothesis (Hypothesis I), adopted by Reis et al. [17].

\subsubsection{Hypothesis I (original from REIS et al. [17]) - 1st flexural $^{\text {st }}$ mode is considered direction to assess second-order effects}

Hypothesis I is the original hypothesis presented by Reis et al. [17]. The selected natural period of vibration is computed to determine the $\chi_{T}$ parameter; only first flexural vibration mode is taken in account to consider global second-order effects. Reis et al. [17] have used the effective modal mass coefficient as the value used to determine the first flexural mode of vibration. According to Reis et al. [17] the natural period of vibration must be chosen if the respective mode shape presents an effective modal mass coefficient greater than $35 \%$ in the considered direction of the global second-order analysis.

Cases, in which none of the first vibration modes present greater effective modal mass than $35 \%$ in any direction, are hardly found. If this is the situation, it must be considered the vibration mode which depict the greatest effective modal coefficient in the assessed direction when compared to the orthogonal directions. This hypoth- esis contributes to further development of Reis et al. [17] studies by verification of its applicability in structural models with several irregularity patterns.

\subsubsection{Hypothesis II - First mode shape of vibration (fundamental vibration mode)}

In this hypothesis, the selected vibration mode is the fundamental mode shape, independently from the assessed direction and the vibration mode shape. This analysis intends to verify the consequences of applying the simplified parameter without the concern regarding the vibration mode shape (flexural, torsional or flexuraltorsional). In addition, this hypothesis will help understanding the application of the fundamental vibration mode as an indicator of the global second-order effects in three-dimensional frames.

\subsubsection{Hypothesis III - Average of the natural period of vibration weighted by the modal participation factor}

The selected period of vibration in this hypothesis is the composition of natural period of vibration weighted by the effective modal mass in the direction considered the greatest second-order effects impact. Herein, the weighted natural period of vibration can be obtained by Equation [3]:

$T_{\text {WeightedAverage }}=T_{1} U_{1}+T_{2} U_{2}+\cdots+T_{n} U_{n}$

In which, $T_{n}$ is the natural period of vibration of the $n$-th mode and, $U_{n}$ the modal participation factor of the $n$-th mode in the considered direction. This hypothesis aims to verify the influence of the higher modes of vibration in the structure sensitiveness to the global second-order effects.

To illustrate hypothesis III natural period selection method, the first vibration modes of a 21-storey building (Model 2 geometry) are shown in Table [3]. Weighted by the effective modal mass, the weighted natural period of vibration in the assessed direction is calculated. In this example, it is intended to calculate the moment amplification $\left(\mathrm{M}_{2} / \mathrm{M}_{1}\right)$ in the $y$-direction using the $\chi_{T}$ parameter. From the presented effective modal mass in Table [3], the weighted period of vibration of hypothesis III is $5.49 \mathrm{~s}$. The definition of the number of vibration modes to be used in this hypothesis was performed through a comparative study, in which the number of selected vibration modes were varied, according to the total effective modal mass participation. The total effective modal mass varied from $75 \%$ to $90 \%$ in the assessed direction. 
The goal is to define the minimum number of vibration modes to be considered on Hypothesis III. Analyses were carried out for the models from Figures [2] to [6] with 10-storey, 20-storey and the maximum number of for each model. The results of this comparison are presented in Table [4]. Difference between the results obtained considering $75 \%$ and $90 \%$ of the total effective modal mass is small. The maximum difference, considering all the structures, was $2.4 \%$. Therefore, the contribution can be disregarded and, it is recommended to adopt the number of natural periods that adds to $75 \%$ of total effective modal mass in the assessed direction ( $x$ or $y$ ).

\section{Results and discussion}

Modal analysis and second-order analysis results of each model are depicted in Figures [8]-[12]. From the modal analyses, curves were plotted referent to the effective modal mass percentage of the first vibration mode as a function of the number of floors for each model. From the global second-order analysis, the bending mo- ment amplification factor $\left(M_{2} / M_{1}\right)$ of all columns in each direction were plotted for every node in the model (gray dots), as a function of the number of storey. Moment amplification factors lower than an unity were disregarded. Columns located at the base were defined as critical columns and, its moment amplification factors are highlighted in the graph, as an analysis criterion.

Adopting the criteria of each hypothesis presented above, the natural period of vibration was selected and used to calculate the simplified $\chi_{T}$ parameter. The dashed vertical line in each graph indicates a change in the first vibration mode type (flexural, torsional, flexural-torsional, etc.) of the structure as a function of the number of storey. Table [5] presents a descriptive legend aimed to summarize the analyses discussed herein; each hypothesis is represented by a different type and line color. The simplified $\gamma_{z}$ parameter, presented in the Brazilian standard ABNT NBR 6118:2014 [2], is also plotted for comparison and validation of the obtained results. Following, a detailed discussion is presented for the modal analysis and the global second-order effects analysis through the simplified $\chi_{T}$ parameter.

\section{Table 4}

Comparative analysis between $\chi_{T}$ values obtained with hypothesis III, varying the number of modes of vibration in function of total mobilized mass $-75 \%$ and $90 \%$

\begin{tabular}{|c|c|c|c|c|c|c|c|}
\hline \multirow{2}{*}{ Model } & \multirow{2}{*}{ Direction } & \multicolumn{2}{|c|}{ 10-Storey } & \multicolumn{2}{|c|}{ 20-Storey } & \multicolumn{2}{|c|}{ Maximum number of storey } \\
\hline & & $75 \%$ & $90 \%$ & $75 \%$ & $90 \%$ & $75 \%$ & $90 \%$ \\
\hline \multirow{2}{*}{1} & $X$ & 1,027 & 1,028 & 1,069 & 1,077 & 1,079 & 1,089 \\
\hline & Y & 1,122 & 1,036 & 1,112 & 1,132 & 1,153 & 1,158 \\
\hline \multirow{2}{*}{2} & $\mathrm{X}$ & 1,052 & 1,057 & 1,147 & 1,166 & 1,159 & 1,179 \\
\hline & Y & 1,066 & 1,068 & 1,235 & 1,252 & 1,261 & 1,277 \\
\hline \multirow{2}{*}{3} & $\mathrm{X}$ & 1,044 & 1,049 & 1,124 & 1,138 & 1,205 & 1,230 \\
\hline & Y & 1,035 & 1,035 & 1,146 & 1,150 & 1,302 & 1,303 \\
\hline \multirow{2}{*}{4} & $\mathrm{X}$ & 1,044 & 1,045 & 1,117 & 1,131 & 1,428 & 1,453 \\
\hline & Y & 1,023 & 1,023 & 1,086 & 1,088 & 1,378 & 1,393 \\
\hline \multirow[b]{2}{*}{5} & $X$ & 1,024 & 1,025 & 1,100 & 1,103 & 1,046 & 1,047 \\
\hline & $\mathrm{Y}$ & 1,046 & 1,047 & 1,179 & 1,185 & 1,082 & 1,084 \\
\hline \multirow{2}{*}{6} & $x$ & 1,014 & 1,015 & 1,055 & 1,057 & 1,119 & 1,123 \\
\hline & $\mathrm{Y}$ & 1,035 & 1,038 & 1,121 & 1,128 & 1,251 & 1,265 \\
\hline \multirow{2}{*}{7} & $x$ & 1,010 & 1,011 & 1,031 & 1,033 & 1,082 & 1,083 \\
\hline & Y & 1,019 & 1,020 & 1,058 & 1,061 & 1,172 & 1,177 \\
\hline \multirow{2}{*}{8} & $X$ & 1,016 & 1,017 & 1,047 & 1,048 & 1,108 & 1,113 \\
\hline & Y & 1,015 & 1,015 & 1,038 & 1,039 & 1,082 & 1,086 \\
\hline \multirow{2}{*}{9} & $X$ & 1,067 & 1,069 & 1,197 & 1,204 & 1,207 & 1,215 \\
\hline & Y & 1,070 & 1,072 & 1,258 & 1,268 & 1,256 & 1,287 \\
\hline
\end{tabular}

\section{Table 5}

Informative legend for the result graphs

\begin{tabular}{|c|c|c|}
\hline Legend & Name & Description \\
\hline & $\chi_{T\left(1-1^{\text {st }} \text { Flexural Mode Reis et al. (2017)) }\right.}$ & Hypothesis I ( $1^{\text {st }}$ flexural mode) \\
\hline---1 & $\chi_{\mathrm{T}\left(I I-1^{\text {st }}\right.}$ Mode of Vibration) & Hypothesis II (fundamental mode of vibration) \\
\hline & $\chi_{\mathrm{T}(\mathrm{III}-\text { Weighted Average) }}$ & Hypothesis III (weighted average) \\
\hline o & Columns & Columns Amplification $\mathrm{M}_{2} / \mathrm{M}_{1}$ \\
\hline & $\gamma_{z}$ & Coefficient $\gamma_{z}$ values \\
\hline$\square$ & Critical columns & Critical columns amplification $\mathrm{M}_{2} / \mathrm{M}_{1}$ \\
\hline
\end{tabular}




\subsection{Modal analysis}

The structure's dynamic characteristics are investigated through the modal analysis. The first vibration mode shapes and the respective natural period of vibration were determined. Figures [8] and [9] present the effective modal mass percentage for the fundamental vibration mode in the $x$-direction, $y$-direction and rotation along the $z$ axis as a function of each assessed geometry. The graphs depict the fundamental vibration mode according to the number of storey. Therefore, the direction with more significant effective modal mass values indicate the structure's type of the vibration mode shape. In Figure [8], for instance, the $y$-direction curve for Model 1 pres-

\section{Model 1}

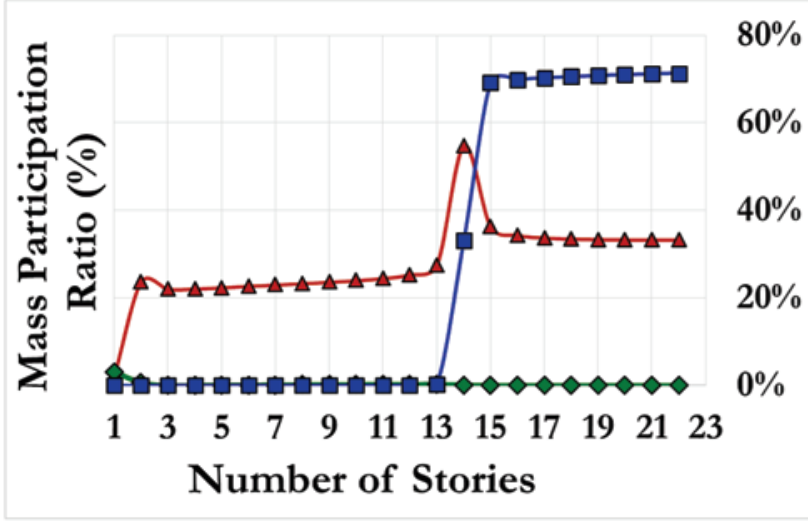

Model 3

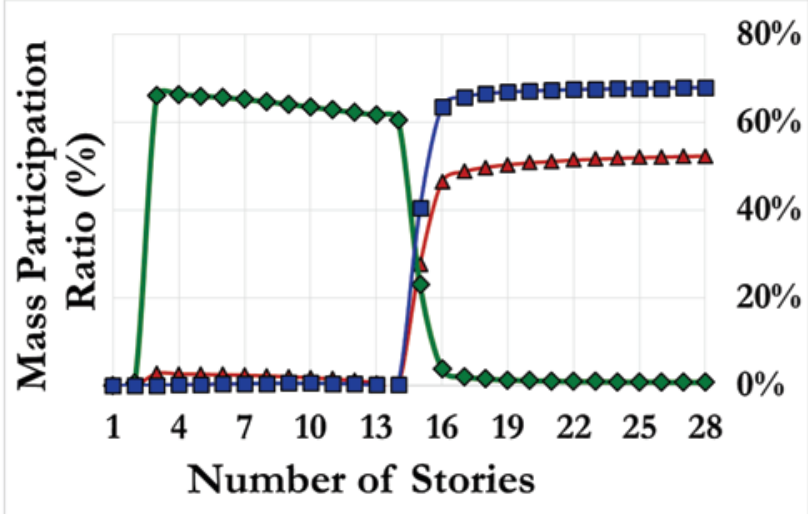

Model 5

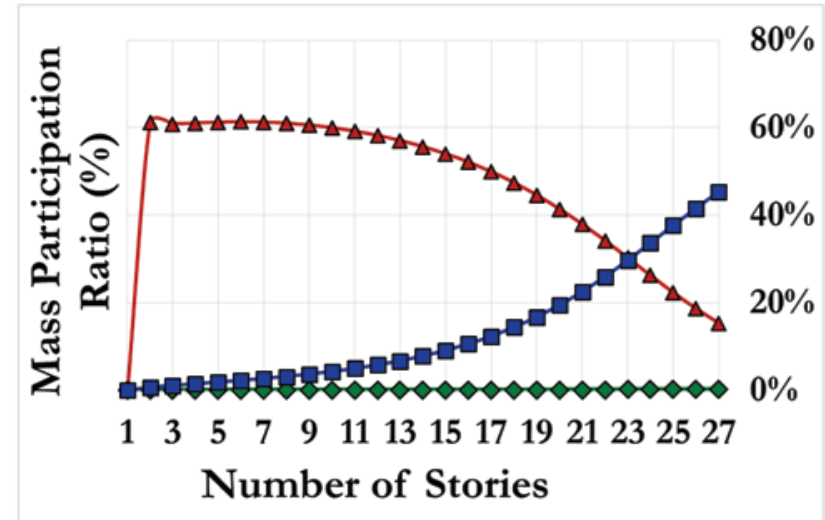

\section{Model 2}

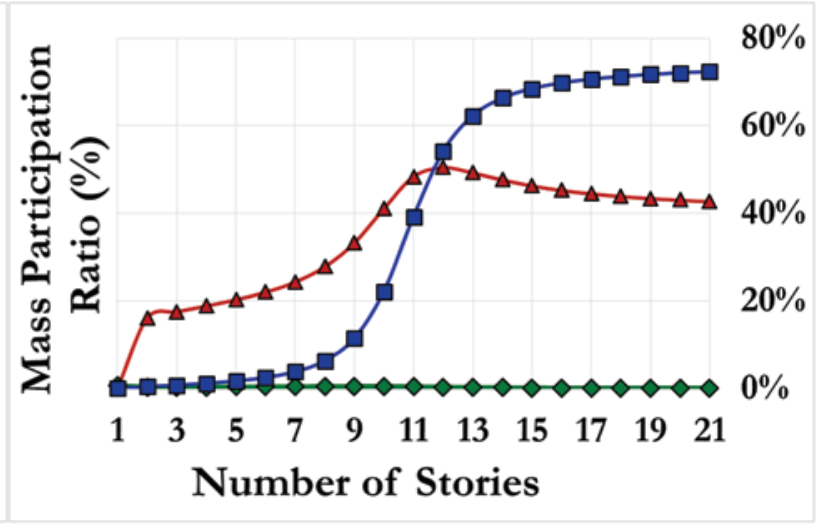

Model 4

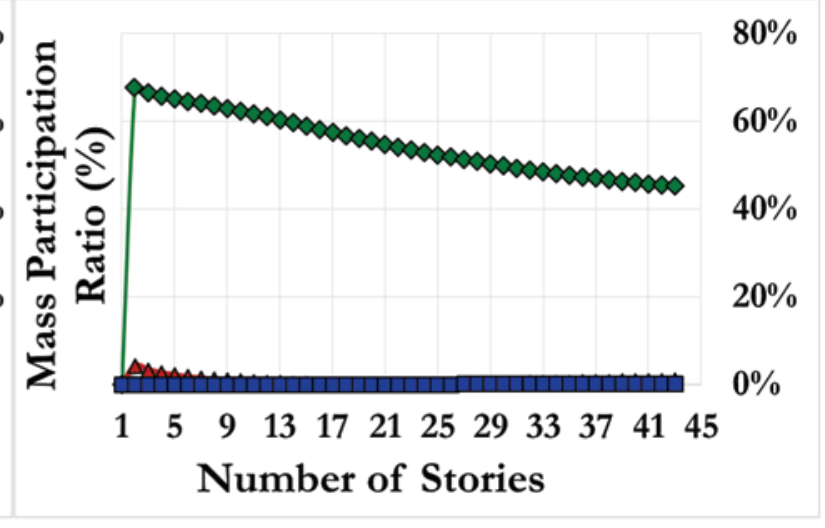

$\longrightarrow x$-direction

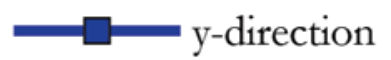

Model 6

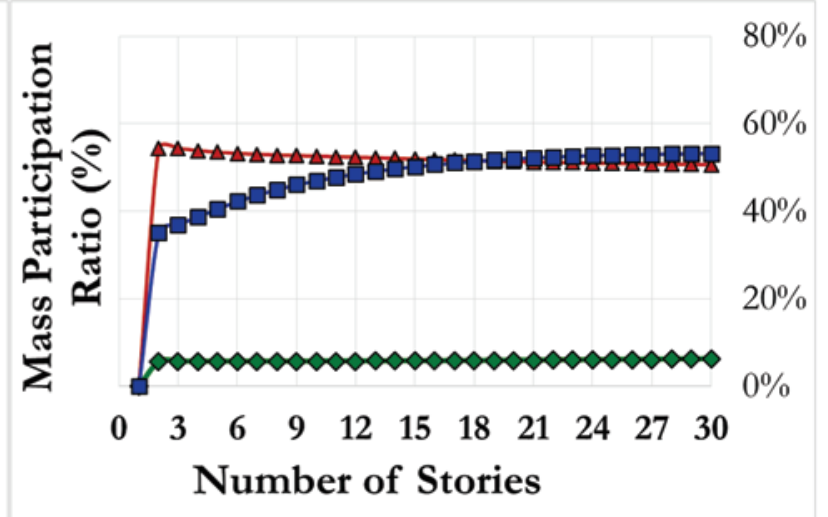

Figure 8

Effective modal mass of the first mode of vibration for models 1, 2, 3, 4, 5 and 6 
Analysis of the global second-order effects on irregular reinforced concrete structures using the natural period of vibration

Table 6

Fundamental mode of vibration direction as function of the number of storey for the assessed models

\begin{tabular}{ccccc}
\hline \multirow{2}{*}{ Models } & \multicolumn{4}{c}{$\mathbf{1}^{\text {st }}$ mode of vibration (fundamental) } \\
\cline { 2 - 5 } & X-Flexural & Y-Flexural & Torsional & Y-Flexural/Torsional \\
\hline 1 & - & $15-22$ Storey & $1-14$ Storey & - \\
2 & - & $12-21$ Storey & $1-11$ Storey & - \\
3 & $1-14$ Storey & - & - & - \\
4 & $1-43$ Storey & - & $14-28$ Storey \\
5 & - & $24-27$ Storey & - & - \\
6 & - & $9-30$ Storey & $3-8$ Storey & - \\
7 & - & - & $3-7$ Storey & - \\
8 & $8-33$ Storey & $14-21$ Storey & $1-13$ Storey & - \\
9 & - & & & - \\
\hline
\end{tabular}

ents an increase on the effective modal mass for the models with 14 storey or more in comparison to the other directions. Below 14 storey, the predominant mode shape is torsional mode shape. Table [6] summarizes the fundamental vibration mode type of all models as a function of the number of storey.

Table [6] depicts also a great number of geometries with torsional vibration mode, which, indirectly, represents structures vulnerable to torsional effects. It must be pointed out that this behavior is usually avoided in the structural design because of the requirement of special rebar detailing related to torsional forces and additional lateral displacements that can be caused due to the combined action of torsion and bending moments. These structures, however, are studied to verify the simplified $\chi_{\mathrm{T}}$ parameter capacity in evaluating the global second-order effects in structures with significant eccentricity between the rigidity center and mass center.

\subsection{Global second-order effects analysis ( $\chi_{T}$ parameter)}

The global second-order effect was evaluated through a P- $\Delta$ analysis. Its bending moment amplification results for each column are plotted for every node. It is intended to compare the bending moment amplification from a more accurate analysis, the P- $\Delta$ analysis, and the moment amplification from the $\chi_{\mathrm{T}}$ parameter.
Model 7

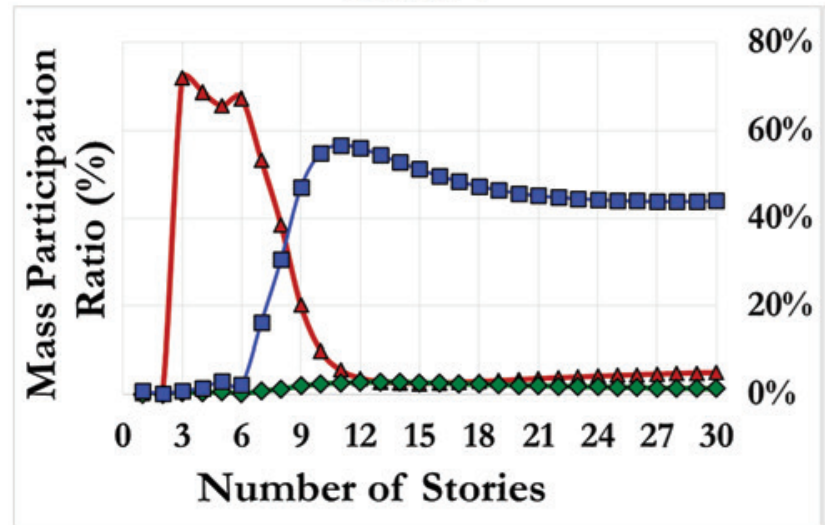

Model 8

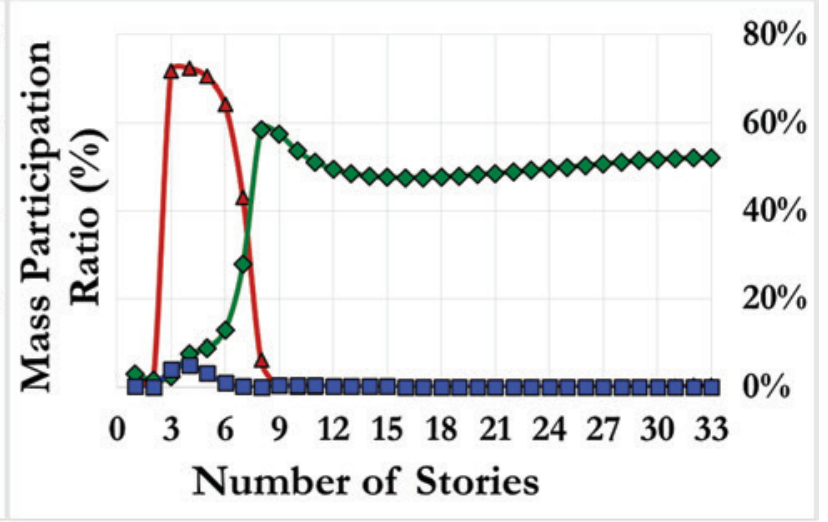

Model 9

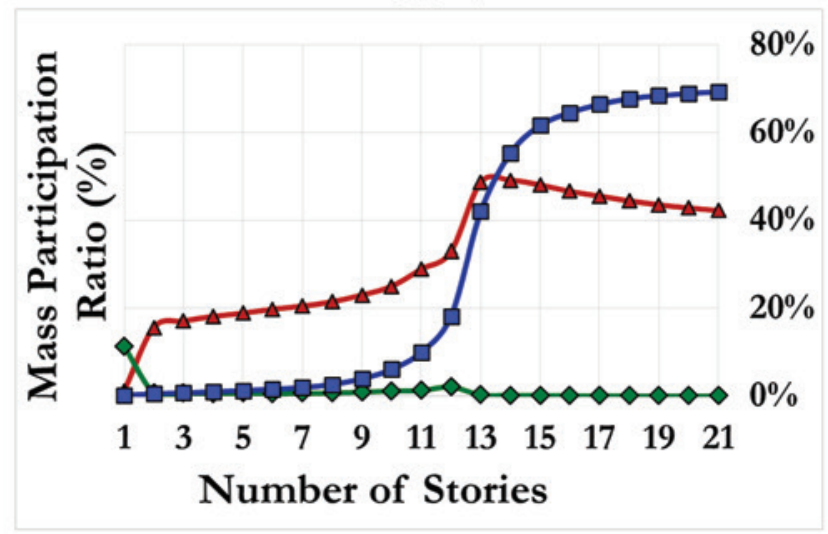

$\curvearrowright x$-direction
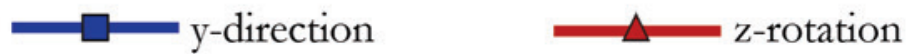

Figure 9

Effective modal mass of the first mode of vibration for models 7,8 and 9 
Model 1- x

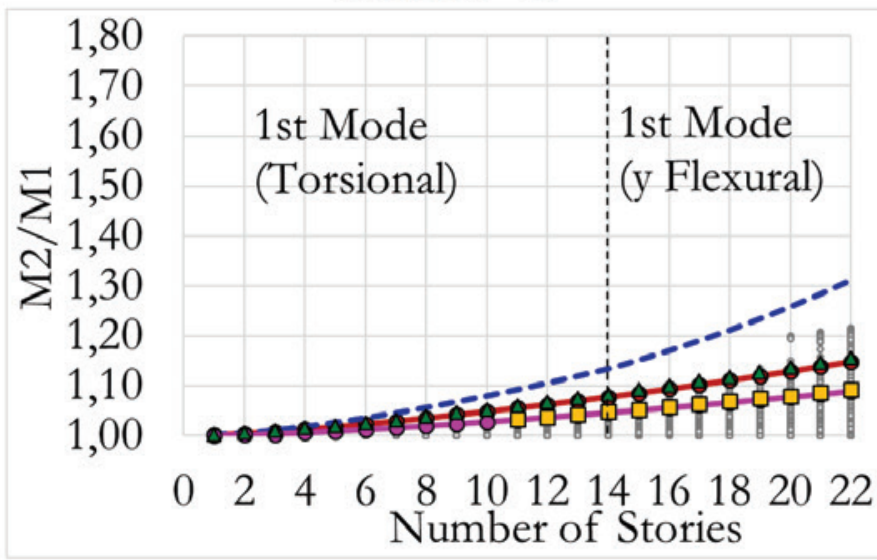

Model 2-x

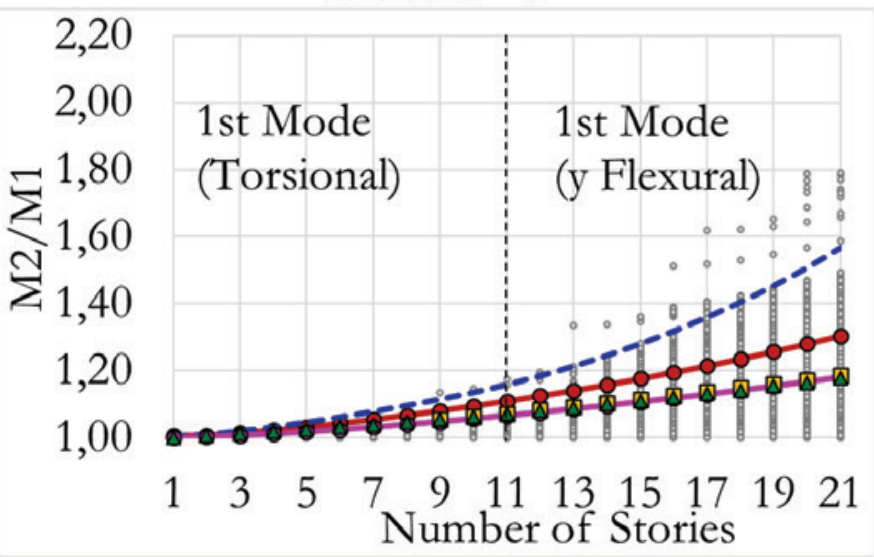

Model 3-x
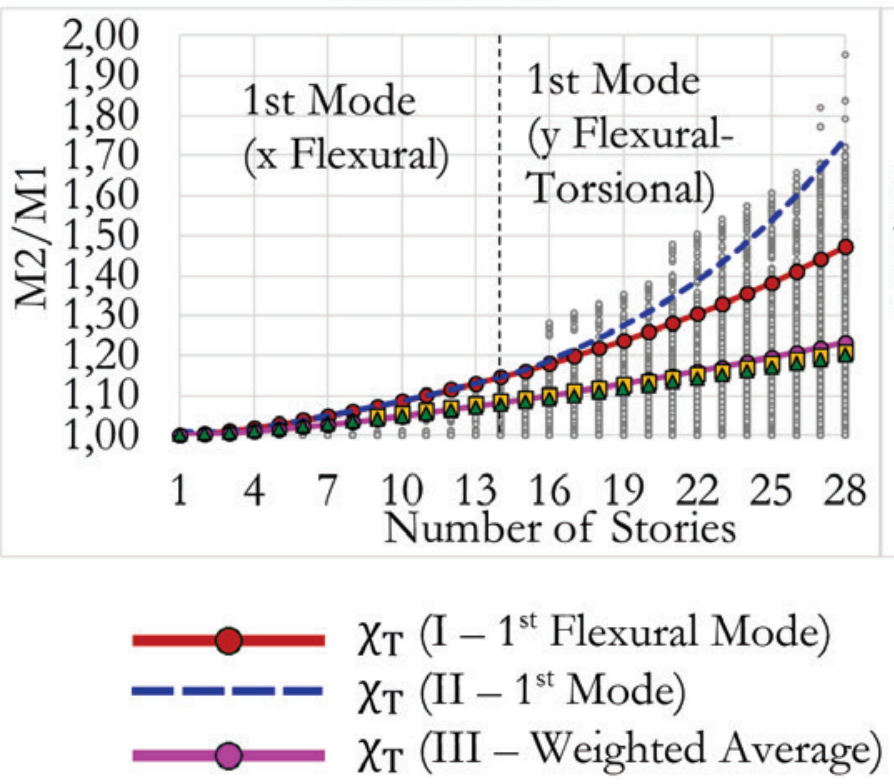

Model 1 - y

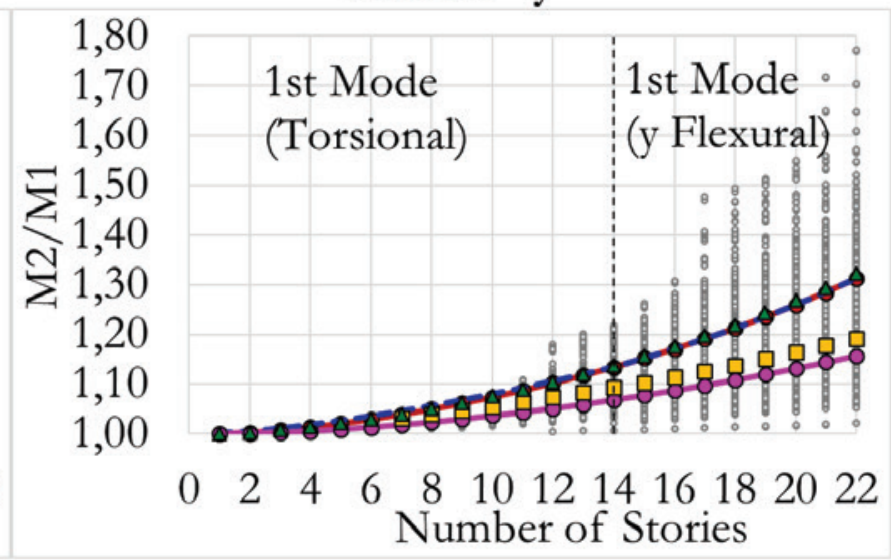

Model 2 - y

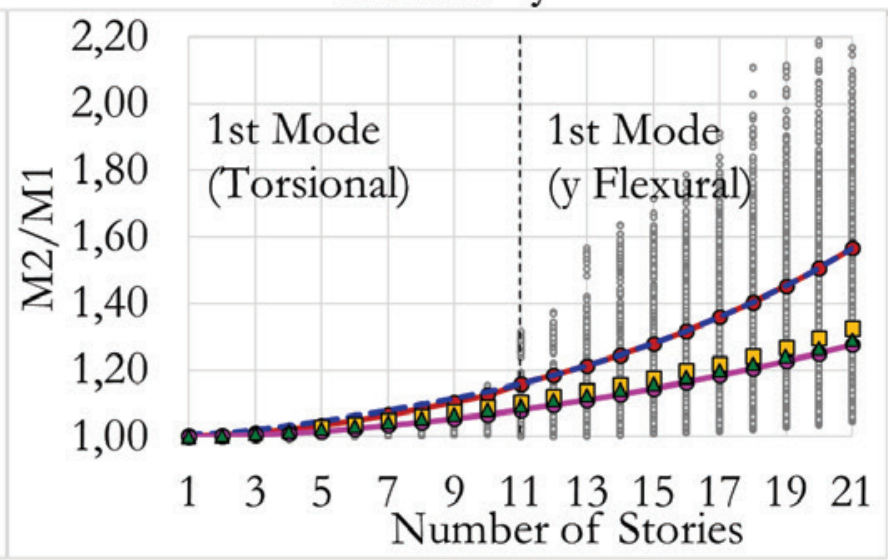

Model 3 - y

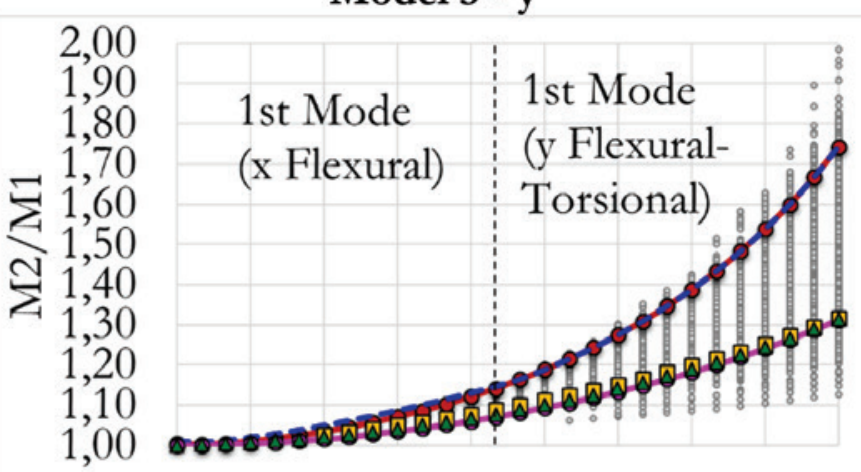

$\begin{array}{llllllllll}1 & 4 & 7 & 10 & 13 & 16 & 19 & 22 & 25 & 28\end{array}$ Number of Stories

$\begin{array}{ll}- & \text { Columns } \\ \square & \text { Critical Columns } \\ \Delta & \gamma_{z} \text { Parameter }\end{array}$

\section{Figure 10}

Moment amplification $\mathrm{M}_{2} / \mathrm{M}_{1}$ in function of the natural period of vibration in the assessed direction Models 1, 2, 3 
Model 4-x

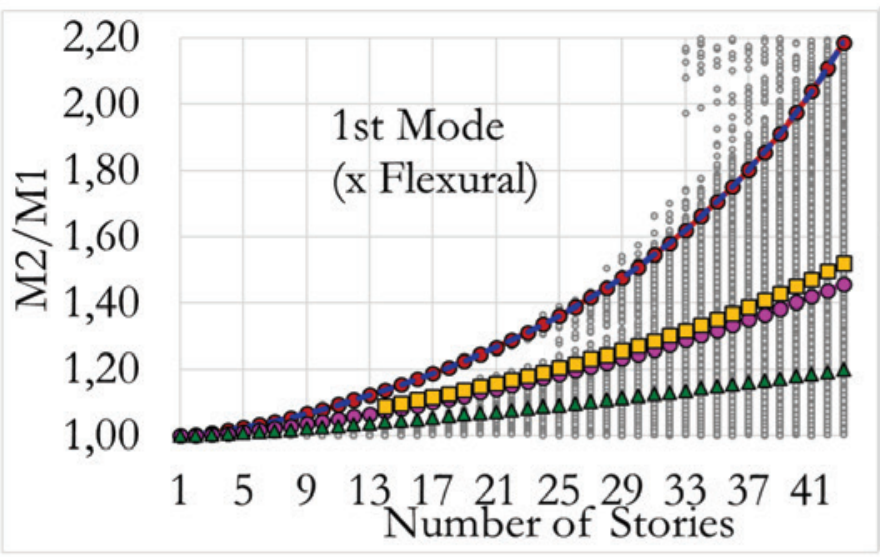

Model 5-x

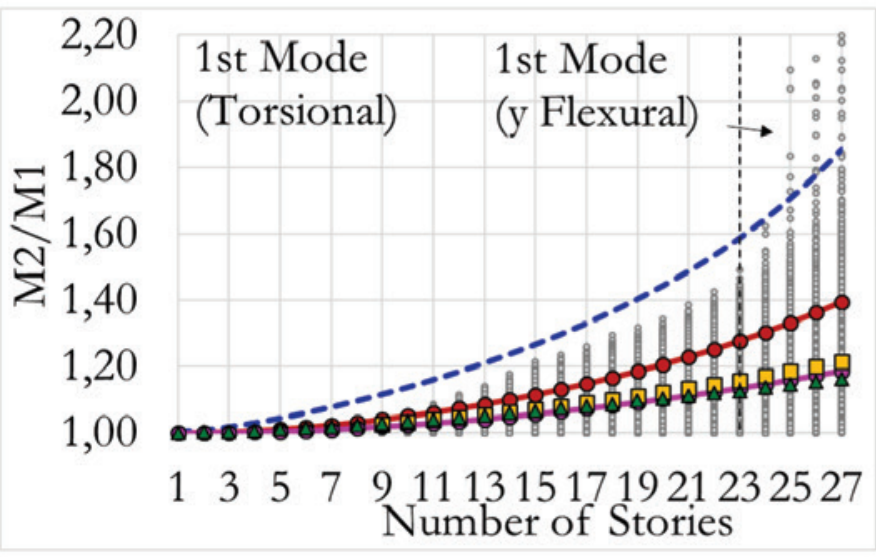

\section{Model 6-x}
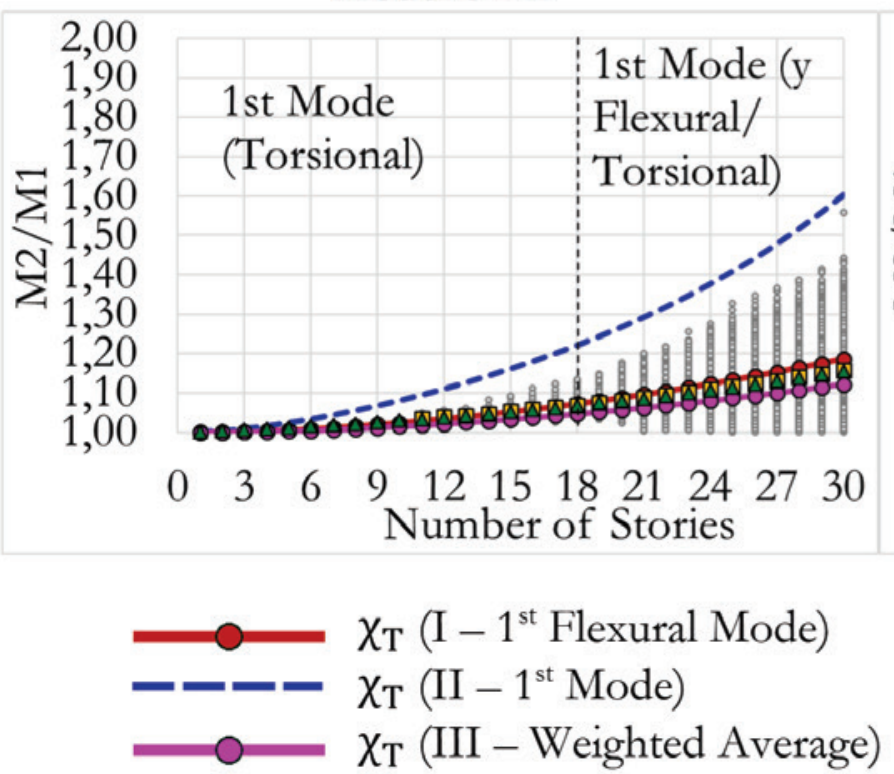

Model 4 - y

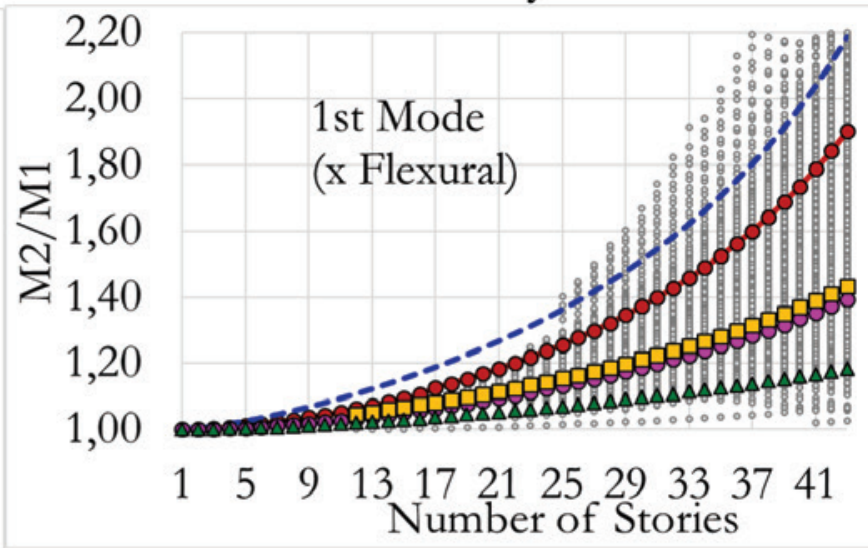

Model 5 - y

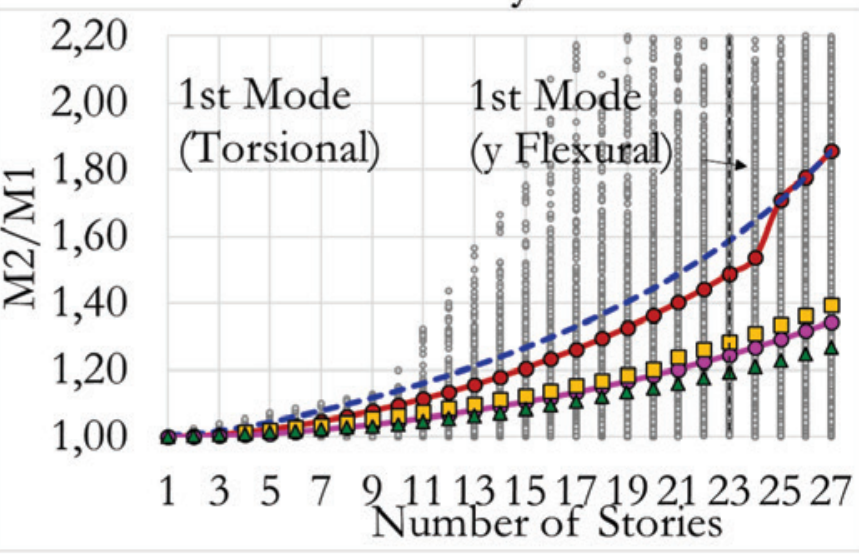

Model 6-y

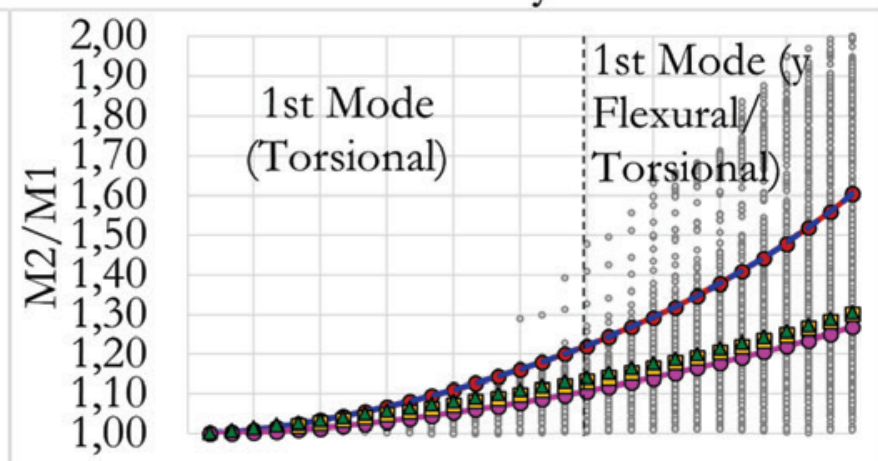

$\begin{array}{lllllllllll}0 & 3 & 6 & 9 & 12 & 15 & 18 & 21 & 24 & 27 & 30\end{array}$ Number of Stories

$\begin{array}{ll}\circ & \text { Columns } \\ \square & \text { Critical Columns } \\ \Delta & \gamma_{z} \text { Parameter }\end{array}$

\section{Figure 11}

Moment amplification $\mathrm{M}_{2} / \mathrm{M}_{1}$ as function of the natural period of vibration in the assessed direction Models 4, 5, 6 
Model 7 - x
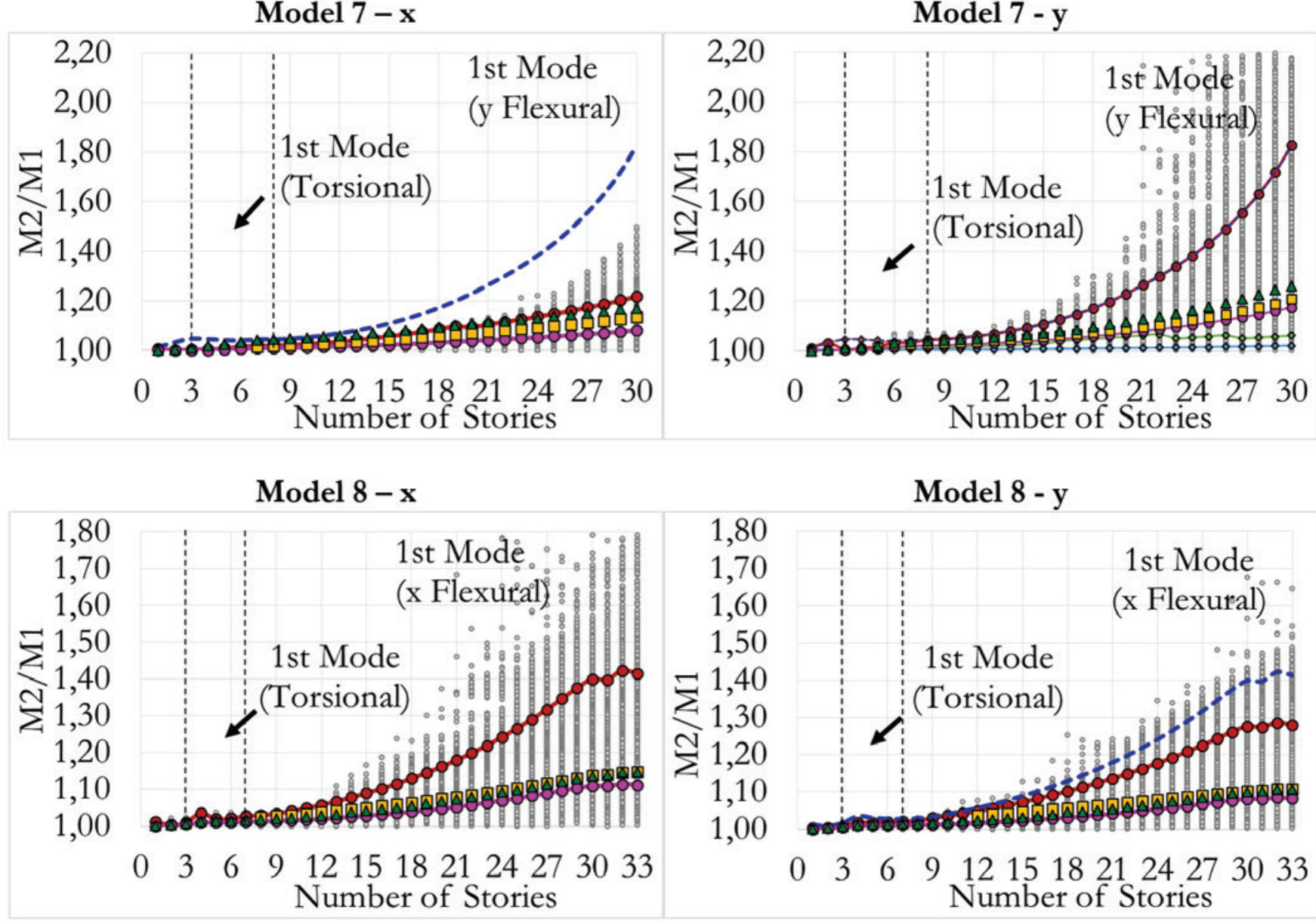

Model 9-x
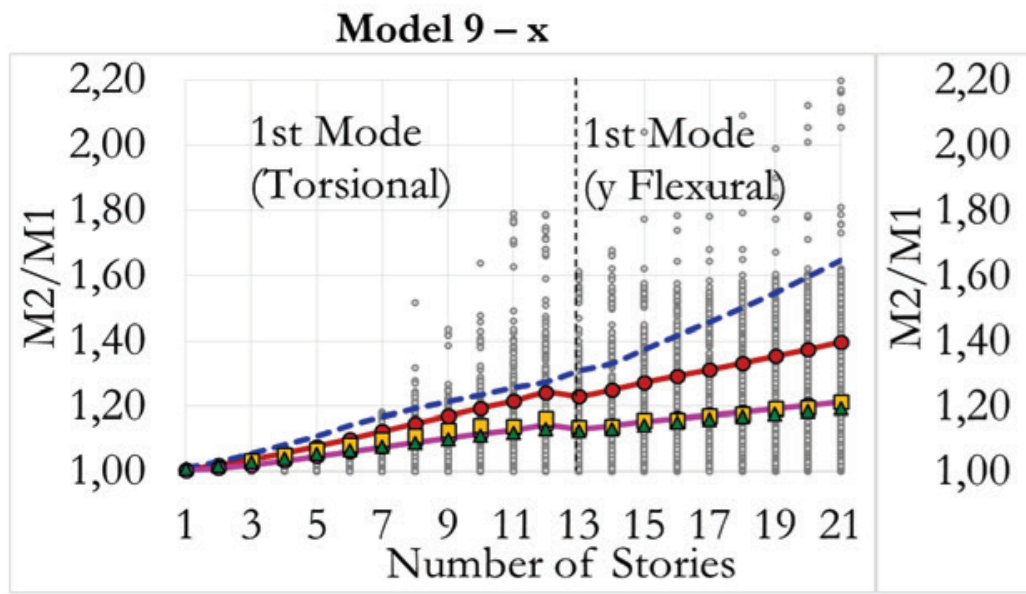

Model 9 - y
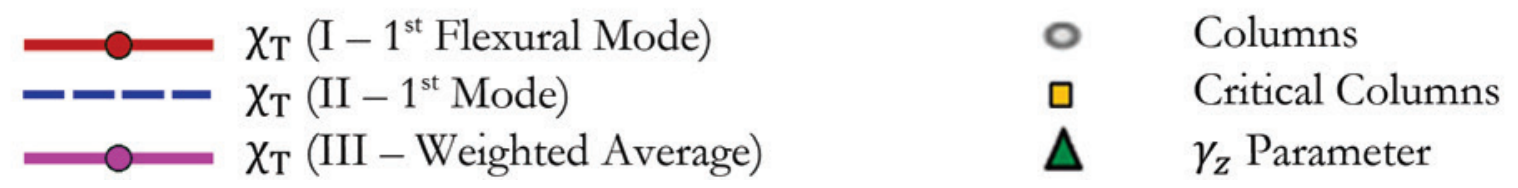

Figure 12

Moment amplification $\mathrm{M}_{2} / \mathrm{M}_{1}$ as function of the natural period of vibration in the assessed direction Models 7, 8, 9 
Figure [10], [11] and [12] show the results of the global secondorder effects in the $\mathrm{x}$ and $\mathrm{y}$-direction, where all hypotheses results are compared, for each model and direction. The moment amplification obtained with the P- $\Delta$ analyses are presented as a function of the number of storey.

It must be emphasized that, the comparison intends to verify the simplified $\chi_{\mathrm{T}}$ parameter accuracy to evaluate global second-order effects in regular and irregular three-dimensional frames. Then, it is expected to evaluate limitations in the use of the $\chi_{T}$ parameter. For instance, using the fundamental natural period of vibration, independently of the direction, the $\chi_{T}$ parameter is evaluated in structures with torsional and flexural-torsional vibration modes. Also, the influence of higher vibration modes is studied.

The bending moment amplification factor calculated using the simplified $\chi_{\mathrm{T}}$ parameter (Hypothesis I) and the bending moments in the critical columns increase with the number of storey in each model, as mentioned by Reis et al. [17]. This systemic increase reinforces that the natural period of vibration and moment amplification due to global second-order effects are related.

As expected, the most flexible direction presented the greatest values for the moment amplification factor. However, it is noticed that when there is a change in the first vibration mode shape, the results for the $\chi_{T}$ parameter and the critical columns are significantly different. One can clearly note that, observing the results for Model 5 in the y-direction. At the point that the first mode of vibration changes from torsional to flexural in y-direction, the parameter curve has a pronounced shift. In this model, for structures with 23 storey or less, the first flexural mode of vibration in the y-direction is the second global vibration mode. Thus, in hypothesis $I$, it is the second natural period of vibration that must be used (Figure [11]). For structures, with more than 23 storey, the fundamental vibration mode (first vibration mode) is flexural. For the 24-storey building, specifically, the fundamental mode of vibration in $y$-direction has an effective modal mass less than $35 \%$. Therefore, in Hypothesis $\mathrm{I}$, the second natural period of vibration was adopted for the simplified parameter calculation. Only in structures with more than 25 storey, the first vibration mode in y-direction present effective modal mass participation greater than $35 \%$, which explains the shift in Hypothesis I curves on Figure [11].
The fundamental mode of vibration meets the hypothesis criteria and, therefore, the natural period of vibration that must be used is the fundamental natural period of vibration, which increases significantly the $\chi_{\mathrm{T}}$ parameter. It can be observed that Hypothesis I, adopted originally by Reis et al. [17], reaches conservatives values for the moment amplification factor, when compared only with the moment amplification factor for the critical columns. It represents a upper bound for the other structure columns [17]. Comparing the $\chi_{\mathrm{T}}$ parameter (hypothesis I) with $\gamma_{\mathrm{z}}$ parameter, Model 1 presented values similar, with maximum difference of $0,71 \%$ between both parameters. This behavior was also noted in Model 6 for the $\mathrm{x}$-direction. The maximum difference was $2,60 \%$ in the 30 -storey structure. If this comparison is carried out for the other models, however, the differences were pronounced, indicating conservative values for the $\chi_{T}$ parameter in relation to $\gamma_{z}$ parameter.

One can note that the torsional mode is the fundamental vibration mode as shown in frames with 14 storey or less for Model 1 , frames with 10 storey or less for Model 2 and, frames with 23 storey or less for Model 5.

For these structures, it is observed that the $\chi_{T}$ parameter given the first vibration mode (fundamental period - hypothesis II) is similar to the $\chi_{T}$ parameter from the original hypothesis proposed by Reis et al. [17] (hypothesis I), when considering the direction with smaller stiffness. Although the fundamental vibration mode is torsional, the results similarity is due to the second mode shape being flexural; the maximum difference being of $8,0 \%$. Table [7] presents the first three vibration modes characteristics for Models 1, 2, 5 and 9, that showed similar results.

For Model 1, the maximum difference between hypotheses I and II curves was $0,66 \%$ in a 14 -storey building. It can be observed in Table [7], that the first vibration mode of Model 1 was torsional, and the second vibration mode was flexural in the $y$-direction. Thus, the $\chi_{\mathrm{T}}$ parameter calculated with hypothesis II (first mode) considers the first natural period of vibration (3,39 s), while hypothesis I (first flexural mode of vibration in the considered direction) considers the value corresponding to the second period of vibration $(3,38 \mathrm{~s})$. The natural periods of vibration are very similar, which explains the small difference between the curves. One can also note this observation in Model 2 in the y-direction. The maximum difference

\section{Table 7}

Structures modes of vibration of Models 1,2,5 and 9

\begin{tabular}{|c|c|c|c|}
\hline Model & Model of vibration & $\begin{array}{c}\text { Natural period of vibration } \\
\text { (s) }\end{array}$ & Mode of vibration type \\
\hline \multirow{3}{*}{$\begin{array}{l}\text { Model } 1 \\
\text { (14-Storey) }\end{array}$} & $1^{\circ}$ & 3.39 & Torsional (rotation along z-axis) \\
\hline & $2^{\circ}$ & 3.38 & Flexural in y-direction \\
\hline & $3^{\circ}$ & 2.64 & Flexural in x-direction \\
\hline \multirow{3}{*}{$\begin{array}{l}\text { Model } 2 \\
\text { (10-Storey) }\end{array}$} & $1^{\circ}$ & 2.95 & Torsional (rotation along z-axis) \\
\hline & $2^{\circ}$ & 2.84 & Flexural in y-direction \\
\hline & $3^{\circ}$ & 2.50 & Flexural in $x$-direction \\
\hline \multirow{3}{*}{$\begin{array}{l}\text { Model } 5 \\
\text { (23-Storey) }\end{array}$} & $1^{\circ}$ & 7.47 & Torsional (rotation along z-axis) \\
\hline & $2^{\circ}$ & 7.04 & Flexural in y-direction \\
\hline & $3^{\circ}$ & 5.73 & Flexural in $\mathrm{x}$-direction \\
\hline \multirow{3}{*}{$\begin{array}{l}\text { Model } 9 \\
\text { (10-Storey) }\end{array}$} & $1^{\circ}$ & 3.71 & Torsional (rotation along z-axis) \\
\hline & $2^{\circ}$ & 3.44 & Flexural in $\mathrm{x}$-direction \\
\hline & $3^{\circ}$ & 3.34 & Flexural in y-direction \\
\hline
\end{tabular}




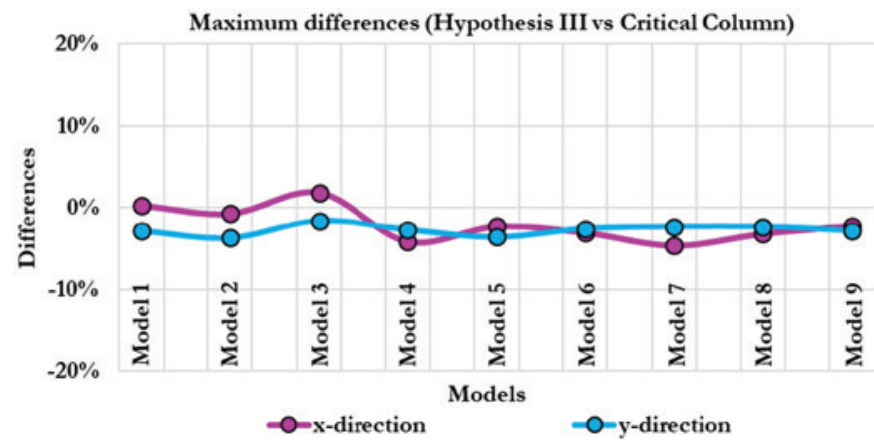

Figure 13

Maximum differences between hypothesis III values and moment amplification for the critical column in each direction of the assessed models

between using hypothesis II (first mode) and the hypothesis I (first flexural mode - Reis et al. [17]) was 1,29\% in a 10-storey building. In Table [7] shall be noted that the first natural period of vibration $(2,95 \mathrm{~s})$ and the first flexural natural period of vibration in the $y$ direction $(2,84 \mathrm{~s})$ have close values. The difference between the natural period of vibration values is $3,87 \%$, which leads the simplified $\chi_{T}$ parameter to similar values in both hypotheses.

When considering these structures flexibility in the x-direction (natural period of vibration presented in Table [7], there is considerably difference between the value of the moment amplification factor for the fundamental period of vibration (hypothesis II) and the other hypotheses. If the fundamental period of vibration is used in threedimensional frames, independently from the assessed direction, the moment amplification for the global second-order effects are conservative when applied to the direction with greatest stiffness. Besides that, once the simplified method is used, the structural engineer is led to verify the building vulnerability to torsion and the authors understand that is an important consideration to be taken in account during the structural design and structural system conception.

On the other hand, the effective modal mass participation factor, aforementioned, is capable to accurately assess the moment amplification factor given that the structure is susceptible to vibration modes with torsional components (flexural-torsional mode shapes). However, considering the value of the natural period of vibration corresponding to the flexural vibration mode, the simplified parameter approaches the moment amplification for the critical columns as an upper bound, particularly in the direction with lower stiffness.
The objective of the hypothesis III development is to verify the influence of higher vibration mode shapes in the $\chi_{T}$ parameter behavior. To assess this hypothesis results, the period of vibration adopted in the parameter is calculated by weighted average of the natural period of vibration, considering the effective modal mass participation in the studied direction.

Hypothesis III results presented values similar to the moment amplification for the critical columns in each direction. Figure [13] presents a comparison between the maximum differences obtained using the $\chi_{\mathrm{T}}$ parameter - hypothesis III and the moment amplification factor for the critical columns of each model. The maximum difference between hypothesis III curves and the moment amplification for the critical columns was $4.65 \%$. This difference was observed considering all geometries from the nine models studied herein, varying the number of storey and the assessed direction for the lateral load ( $x$ and $y)$.

The authors would like to emphasize the importance in considering higher modes of vibration in the simplified $\chi_{T}$ parameter analyses, with the equation presented by Reis et al. [17]. For Model 9 , which were obtained with the redesign of Model 2 as storey were introduced, hypothesis III results are similar to the moment amplification in the critical columns. Note that this structure presents stiffness variation along the building's height and floor-plan asymmetry; these considerations are more realistic situation in structural design.

One can note that, for this model, there are cases in which the moment amplification for the critical columns reduces, as the number of floors increases. This reduction can indicate a case in which the critical column has its participation in the structural global stiffness reduced because of the new design. Or, a case in which, after the redesign, another column was considered critical; in other words, presented higher internal forces.

Figure [14] shows the changes of the elements' dimensions in the ground floor for 12-storey and 13-storey structures. Both models are based on Model 9 geometry. Columns P9 and P17 are highlighted in Figure [14]; these are the columns with the greatest bending moment in the 12-storey and 13-storey buildings, respectively. The overturning moment values of columns P9 and P17 for the 12-storey and 13-storey buildings of Model 9 is presented in Table [8]. Columns' section and moment of inertia is also presented in Table [8]. P9 is the critical column in the 12-storey building. The overturning moment is $144,9 \mathrm{kN} . \mathrm{m}$ and the moment amplification factor $\left(M_{2} / M_{1}\right)$ is equal to 1,16 . For the 13-storey building, however, column P17 presents an overturning base moment of $205,5 \mathrm{kN}$.m, which is greater than the moment in the

\section{Table 8}

Overturning base moment of critical columns for 12-storey and 13-storey structures - Model 9

\begin{tabular}{|c|c|c|c|c|c|c|c|}
\hline $\begin{array}{l}\text { Number of } \\
\text { Storey }\end{array}$ & Column & $\begin{array}{l}\text { Base cross } \\
\text { section } \\
(\mathrm{cm} \times \mathrm{cm})\end{array}$ & $\begin{array}{l}\text { Moment of } \\
\text { Inertia in } \\
\text { x-direction } \\
\left(\mathrm{cm}^{4}\right)\end{array}$ & $\begin{array}{l}1^{\text {st }} \text { order base } \\
\text { moment - M1 } \\
(\text { kN.m) }\end{array}$ & $\begin{array}{c}\text { Final base } \\
\text { moment - M2 } \\
(\mathrm{kN} . \mathrm{m})\end{array}$ & $\begin{array}{l}\text { Amplification } \\
\text { M2/M1 }\end{array}$ & $\begin{array}{l}\text { Critical } \\
\text { column }\end{array}$ \\
\hline \multirow{2}{*}{ 12-Storey } & PQ & $20 \times 88$ & 597226.68 & 124.6 & 144.9 & 1.16 & $x$ \\
\hline & $\mathrm{P} 17$ & $50 \times 50$ & 520833.33 & 108 & 123.5 & 1.14 & - \\
\hline \multirow{2}{*}{ 13-Storey } & P9 & $25 \times 88$ & 767158.33 & 136.3 & 156.5 & 1.15 & - \\
\hline & P17 & $45 \times 65$ & 1029843.75 & 180.8 & 205.5 & 1.14 & $x$ \\
\hline
\end{tabular}


Model 9 - Ground Floor

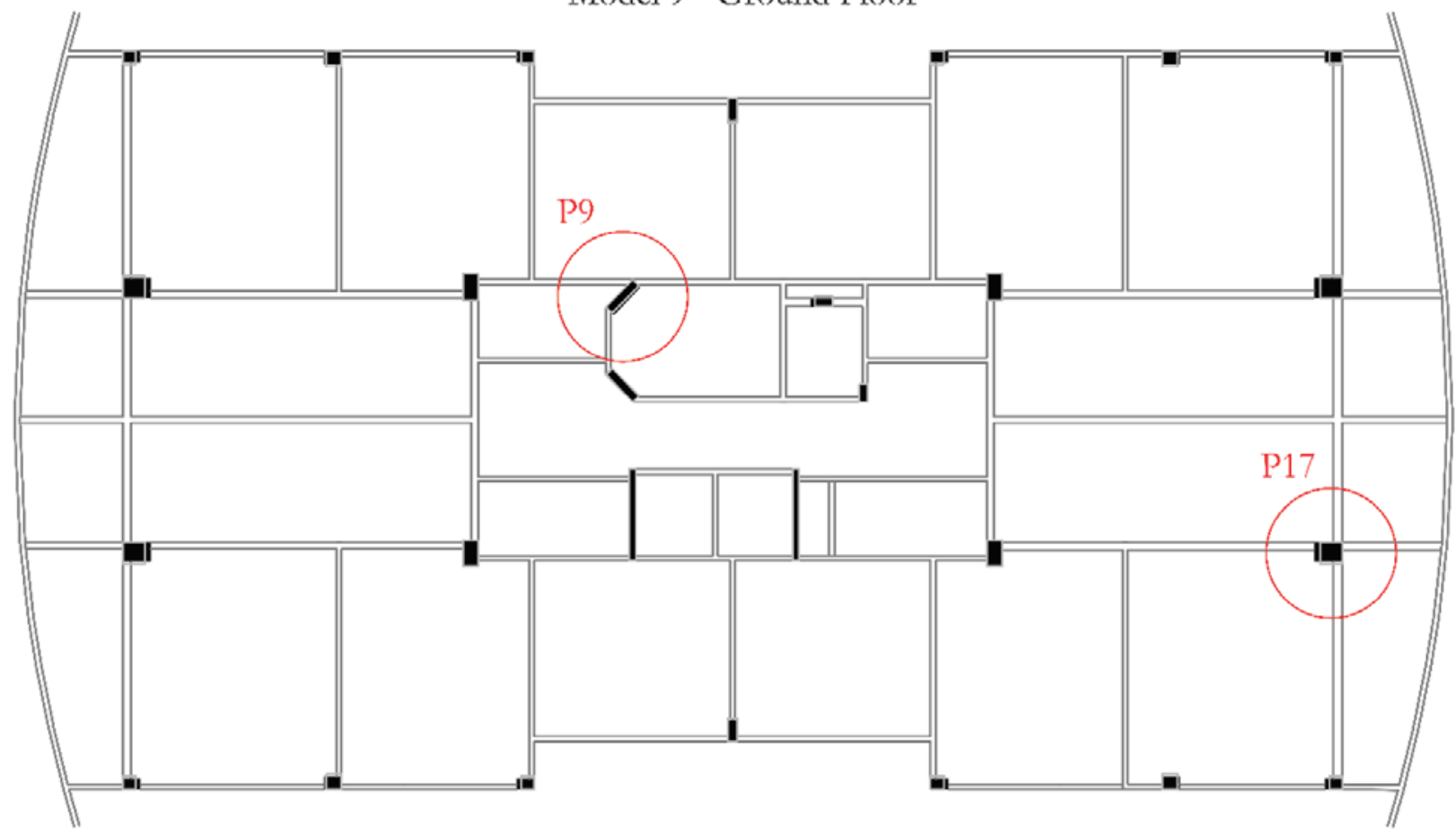

P)

Cross section 12-Storcy $-88 \times 20 \mathrm{~cm}^{2}$ Cross section 13-Storey - $88 \times 25 \mathrm{~cm}^{2}$

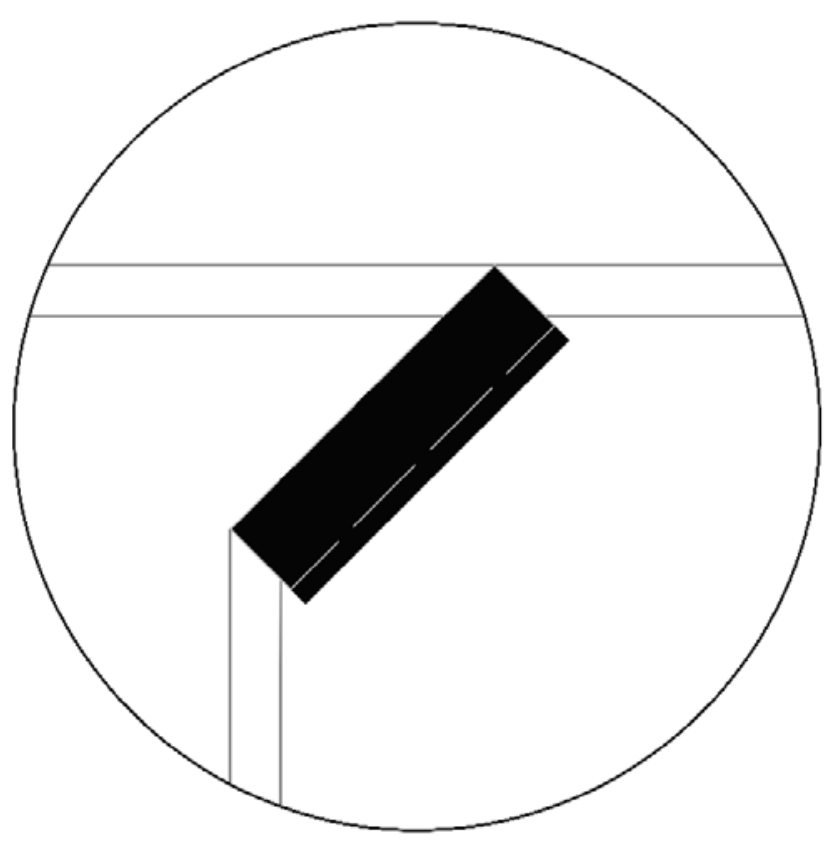

$\mathrm{L}_{---} \mathrm{I}$ Cross section for 12-Storey

Cross section for 13-Storcy

\section{Figure 14}

Cross section of P9 and P17 columns in the ground floor for 12-storey and 13-storey structures - Model 9 
P9 column (156,5 kN.m) and the moment amplification factor is 1,14 . One can note that the moment amplification factor was reduced, even with an increase in the number of storey, from 12 to 13 storey. The reduction is explained by the fact that the critical column is different in both analyses. Hypothesis III curves also presented shifts in the same points in which these changes were noticed. Therefore, the simplified method was also sensitive to these structural behavior changes.

In general, applying the original equation (Hypothesis I) resulted in conservative moment amplification factor in relation to the critical columns. This can be explained by adoption of a displacement function that only satisfies the essential boundary conditions. The weighted natural period of vibration improved significantly the accuracy of the moment amplification factor. The weighting is a correction for the system's stiffening arising from the original formulation. Once the structural system becomes more flexible, there is improvement of the simplified analysis representation for the critical columns.

\section{Conclusions}

This paper presented the applications and limitations of a simplified parameter, based on the natural period of vibration, used to evaluate the global second-order effects on irregular reinforced concrete structures. The objective was to evaluate the $\chi_{T}$ parameter applicability to irregular structures susceptible to torsion. Nine models with different geometries were assessed. The models presented different patterns of irregularity on the floor plan and stiffness variations. In addition, two new hypotheses for the $\chi_{T}$ parameter were proposed. It was intended to verify the importance of the vibration mode direction on the $\chi_{T}$ parameter and, also verify the contribution of the higher vibration modes in the global second-order effects.

The obtained results have demonstrated that the $\chi_{T}$ parameter is a promising estimator for the global second-order effects, even in irregular reinforced concrete structures. More accurate results are found when considering higher vibration modes.

Most of the models studied herein consisted of structures vulnerable to torsion. In other words, structures in which the first natural vibration mode is torsional or, structures with high effective modal mass for the rotation along the vertical axis (z-axis). From the results, it is clear that the simplified method proposed herein is able to capture the moment amplification factor for mixed vibration mode (flexural torsional) or predominantly torsional.

Moreover, the analyses indicate the importance of observing the structure fundamental vibration modes during structural design. Structures with torsional vibration mode as the fundamental mode indicates great eccentricities between the center of mass and center of rigidity, which leads to the conclusion that the structure is vulnerable to torsion and, the effects shall be carefully considered in the structural analysis. In order to avoid this behavior on the design of reinforced concrete frames, some corrective measures can be taken.

In addition, the simplified methodologies usually used to evaluate the global second-order effects have some restrictions on structures with torsional behavior; these methodologies do not present any indication of the fundamental vibration mode or information about the direction of the critical mode.

Therefore, the simplified analysis with the $\chi_{T}$ parameter become an advantageous tool for the structural engineer. The coupled analy- sis considering the modal parameters (period of vibration, vibration mode and, effective modal mass) lead to a better understanding of the type and direction of the structure vibration mode shape. Furthermore, this observation will provide to the structural engineer basis for any necessary precautions related to the structure vulnerability to torsional effects. For the application of the simplified parameter, it must be assured that the parameter is calculated with the periods of vibration associated with the flexural vibration mode for each direction.

The global second order analysis applying the $\chi_{T}$ parameter with hypothesis II (fundamental vibration mode) presented excessively conservative results in the direction of the higher structural stiffness. Therefore, it is important to use the $\chi_{T}$ parameter considering each orthogonal direction in the floor plan. The effective modal mass must be greater than $35 \%$ for the first flexural vibration mode in the assessed direction.

Hypothesis III, which considers an average natural period of vibration weighted by the effective modal mass, presented moment amplification similar to the moment amplification obtained for the critical columns in the design. The latter moment amplification was obtained through a P- $\Delta$ analysis. The maximum difference for the amplification curves of this hypothesis was $4,65 \%$ when compared with the moment amplification of the critical columns.

It must be emphasized that Model 7 and 8 are built structures in Brazil. And, Model 9 structures were redesigned as new storey were introduced, thus, representing real structural systems. These structures have stiffness variation along the building's height. The $\chi_{T}$ parameter with hypothesis III was able to satisfactorily represent the moment amplification for the critical. Therefore, even if the stiffness changes along the building's height, as the modal analysis considers the global stiffness and mass matrices, the simplified parameter is capable of determining the moment amplification for the critical columns (critical in the structural design).

Finally, it must be emphasized that the $\chi_{\mathrm{T}}$ parameter equation used herein was developed considering a uniformly distributed lateral loading, which represents the wind load. New studies, however, may be carried out to adequate the parameter for wind loading variation along the building's height. In order to evaluate the global second-order effects in structures vulnerable to torsional effects, methodologies that consider the dynamic loading effects must be used. For instance, the synthetic wind methodology can be used in further studies.

\section{Acknowledgements}

The authors would like to acknowledge the financial support of the São Paulo Research Foundation (FAPESP) under grant number 2015/18450-8, FAEPEX-UNICAMP under PAPDIC program number 1274/2015 and, and S4 Sistemas Estruturais. This study was financed in part by the Coordenação de Aperfeiçoamento de Pessoal de Nível Superior - Brasil (CAPES) - Finance Code 001.

\section{References}

[1] MONCAYO, W. J. Z.. Análise de segunda ordem global em edifícios com estrutura de concreto armado, São Paulo, 2011, Dissertação (mestrado) - Escola Politécnica, Universidade de São Paulo. 
[2] ASSOCIAÇÃO BRASILEIRA DE NORMAS TÉCNICAS. Projeto de Estruturas de Concreto. - NBR 6118, Rio de Janeiro, 2014.

[3] PINTO, R. S.. Análise não-linear das estruturas de contraventamento de edifícios em concreto armado, São Paulo, 2002, Tese (doutorado) - Escola Politécnica, Universidade de São Paulo.

[4] AZEVEDO, A. F. F. L. C.. Análise tridimensional de estruturas metálicas incluindo os efeitos de segunda ordem, Portugal, 1993, Dissertação (mestrado) - Faculdade de Engenharia, Universidade do Porto.

[5] ZIEMIAN, R. D.. Guide to Stability design criteria for metal structures, Wiley, 6th edition, 2010.

[6] ZALKA, K. A. Global Structural Analysis of Buildings. E \& FN Spon. London. 2000

[7] RUTENBERG, A. A Direct P-Delta Analysis Using Standard Plane Frame Computer Programs. Comput. Struct., Vol. 12.,1981;

[8] WILSON, E. L.; EERI, M. e HABIBULLAH, A.. Static and Dynamic Analysis of Multi-Story Buildings Including P-Delta Effects. Earthquake Spectra, Vol. 3(2), pp. 289-298, 1987.

[9] WHITE, D. W; SUROVEK, A. E. e KIM, S-C. Direct Analysis and Design Using Amplified First-Order Analysis: Part 1 Combined Braced and Gravity Framing Systems. AISC Eng. J., Vol. 44, No. 4, pp. 305-322, 2007a.

[10] WHITE, D. W; SUROVEK, A.E. e CHANG. C-J. Direct Analysis and Design Using Amplified First-Order Analysis. Part 2 Moment Frames and General Framing Systems. AISC Eng. J., Vol. 44(4), pp. 323-340, 2007b.

[11] VANDEPITTE, D.. Non-iterative Analysis of Frames Including the P- $\Delta$-effect. Journal of Constructional Steel Research, Vol. 2(2), pp. 3-10, 1982

[12] AMERICAN INSTITUTE OF STEEL CONSTRUCTION. Specifications for Structural Steel Buildings, Chicago, 2010.

[13] FRANCO, M.; VASCONCELOS, A. C. Practical assessment of second order effects in tall buildings. Coloquium on the CEB-FIP MC90, Rio de Janeiro. Proceedings, p. 307-323, 1991.

[14] VIEIRA, V. V. S.; RODRIGUES JUNIOR, S. J., VELOSO L. A. C. M.. Global stability analysis of reinforced concrete buildings using the $\gamma_{\mathrm{z}}$ coefficient, Revista IBRACON de Estruturas e Materiais, Volume 10, Number 5, p.1113-1140, 2017.

[15] FEITOSA, L. A.; ALVES, E. C.. Study of global stability of tall buildings with prestressed slabs, Revista IBRACON de Estruturas e Materiais 8(2), p.196-209, 2015.

[16] STATLER, D. E.; ZIEMIAN, R. D.; ROBERTSON, L. E.. The natural period as an indicator of second-order effects, in Proceedings of the Annual Stability Conference Structural Stability Research Council, 2011.

[17] REIS, D. G.; SIQUEIRA, G. H.; VIEIRA Jr., L. C. M., ZIEMIAN, R. D.. Simplified approach based on the natural period of vibration for considering second-order effects on reinforced concrete frames. International Journal of Structural Stability and Dynamics, Vol. 18 (5) 2017.

[18] RAYLEIGH, J. W. S. L. Theory of Sound, vol. 2, Dover Publications, New York, 1945.
[19] PAULTRE, P. Dynamics of Structures. Wiley-ISTE, New York, 2010.

[20] MAMONE, R. G.; SIQUEIRA, G. H.; VIEIRA., L. C. M.; The use of natural period of vibration as a simplified indicator of second-order effects for RC frames, International Journal of Structural and Civil Engineering Research Vol. 7, No. 1, February, 2018.

[21] S4 Sistema Building: version 4.0. Developed by S4 Sistemas. Curitiba, 2015. Available in: http://s4sistemas.com.br/.

[22] SAP2000: version 17.3.0. Developed by Computers and Structures, Inc., Berkley, 2015. Available in: http://www.csiamerica.com.

[23] FONTES, F. F. e PINHEIRO, L. M., Analysis of a building by different structural models. Anais do VI Simpósio EPUSP sobre Estruturas de Concreto. SIMP0225 - p.233-250. ISBN 85-86686-36-0, Abril, 2006.

[24] ASSOCIAÇÃO BRASILEIRA DE NORMAS TÉCNICAS. Forças devidas ao vento em edificações. - NBR 6123, Rio de Janeiro, 1988. 